Motivated by Default - How nudges facilitate people to act in line with their motivation

\author{
Van Gestel, Laurens C. ${ }^{* 1}$, Adriaanse, Marieke A. ${ }^{1}, \&$ De Ridder, Denise T. D. ${ }^{1}$ \\ ${ }^{1}$ Department of Social, Health and Organizational Psychology, Utrecht University,
}

Netherlands

Address correspondence to:

* Laurens C. van Gestel

Utrecht University

Heidelberglaan 1

P.O. Box 80140

3508 TC Utrecht, The Netherlands

This work is supported by the Netherlands Organization for Health Research and Development under ZonMW Grant 91215012.

C American Psychological Association, 2021. This paper is not the copy of record and may not exactly replicate the authoritative document published in the APA journal. Please do not copy or cite without author's permission. The final article is available, upon publication, at: $10.1037 / \operatorname{mot} 0000230$ 


\begin{abstract}
Nudges are defined as small adjustments in the choice architecture that help people perform desirable behavior. How nudges interact with individuals' motivation has not been studied empirically. We conducted three studies with different types of defaults in three different behavioral domains and investigated how defaults and different types of motivation affect choice outcomes. In Study 1, we investigated the effectiveness of a default to stimulate healthy eating choices implemented in a hypothetical online supermarket setting. In Study 2, we used a scenario in which participants could choose from a list of green amenities (either preselected or not). In Study 3, we asked participants if they wanted to participate in a basic or longer version of our questionnaire, with the longer version option set as the default in the nudge condition. Across three studies we show that defaults are effective in promoting desirable behavior, and that goal strivings and autonomous motivation have additional positive main effects. We did not find evidence that controlled motivation did affect behavioral outcomes. Exploratory analyses revealed that amotivation negatively affected behavior, but the measure had poor reliability. No significant interaction effects were observed. Together, these studies imply that both defaults and motivation have main effects on behavior, such that the default sets the anchor from which people can adjust according to the type and strength of their motivation. Implications for the practice and ethics of nudging are discussed.
\end{abstract}

Keywords: Nudging; Motivation; Default; Self-Determination Theory 


\section{Motivated by Default - How nudges \\ facilitate people to act in line with their motivation}

People strive for all sorts of outcomes such as living a healthy lifestyle or making sustainable choices. Whatever it is that people strive for, research on self-control as a limited resource (Baumeister et al., 1998; Wilkowski et al., 2018), autonomous and controlled motivation (Deci \& Ryan, 2000), and the intention-behavior gap (Sheeran \& Webb, 2016) - to name just a few examples - suggests that people often experience difficulty in achieving the behavioral end states that they strive for. In many cases, difficulties arise from the non-supportive context of desired behavior. For example, the obesogenic environment makes it complicated to act upon one's intention for healthy eating (Swinburn et al., 1999), while easy access to one's own car makes it more convenient than public transport. In order to make the context more supportive of desired behavior, nudges - subtle changes in the environment that stimulate desirable behavior (Thaler \& Sunstein, 2008) - have been introduced as a novel policy tool. However, the critical question whether effects of nudges depend on motivation has of yet received little empirical scrutiny and requires further research. In the current set of studies, we therefore intend to extend the knowledge base on nudging by studying the role of motivation as a potential moderator of nudges' effectiveness across different behavioral domains. In doing so, we focus on motivation strength (based on research on personal strivings; Emmons, 1986) as well as on different reasons underlying motivation (based on Self-Determination Theory; Ryan \& Deci, 2000). Moreover, we examine the incremental value of nudges on top of existing motivation.

Given its relevance for so many behavioral outcomes, it is remarkable that little is known about how motivation relates to nudging. Thus far, only rather distally related constructs like attitudes and preferences have received attention in studies on nudges' 
effectiveness, while more proximal constructs like needs have only been studied as outcome variables (e.g., Arvantitis et al., 2020; Wachner et al., 2020). Yet, it is important to know both for practical implementation and for the ethical debate about the legitimacy of nudges when and for whom nudges are effective (De Ridder et al., in press). For example, one outstanding question is whether nudges and human motivation independently or interactively predict behavior. It has been suggested that there should at least be some kind of motivation for a nudge to be effective and legitimate (Bovens, 2009; Thaler \& Sunstein, 2008), but whether this is indeed the case and how nudges and motivation together impact behavior is currently not clear. Moreover, it is also not known whether relatively small interventions like nudges can in fact add an increased propensity to perform desirable behavior when accounting for people's motivation. Both questions have, to the best of our knowledge, not been directly addressed in empirical research. In the current set of studies, we aim to advance the field on nudging desirable behavior by looking at motivational strength as well as at different types of motivation as potential moderators of the effect of default nudges in different behavioral domains.

\section{Nudging}

Nudges are defined as subtle changes in the immediate choice environment that alter behavior in a predictable way, without interfering with financial incentives or forbidding any of the available options in the choice set (Thaler \& Sunstein, 2008). The terms 'nudge' or 'nudging' are frequently used as an umbrella term for interventions in the choice environment that steer behavior towards a desirable outcome without relying on the availability of cognitive resources (Hunter et al., 2018; Van Gestel et al., 2020a). This is in contrast to other interventions such as educational campaigns or persuasion techniques which often do rely on the availability of cognitive resources (Beauchamp et al., 2014; Lorenc 
et al., 2013; McGill et al., 2015). Nudges are therefore an interesting and novel policy instrument, exactly because the change in the environment does not require educating or training individuals, because it has the potential to reach many individuals, and because of high cost-effectiveness (Benartzi et al., 2017).

The interventions that fall under this umbrella term 'nudging' come in all sorts and shapes, ranging from interventions that rely on social proof (e.g., Venema et al., 2020) or environmental restructuring (e.g., Van Gestel et al., 2018; Van Gestel et al., 2020b). One of the most prototypical and robust examples of nudges are defaults (e.g., Johnson \& Goldstein, 2003; Van Gestel et al., 2020a), which determine the choice outcome in case no active decision is made. That is, if people do not actively opt-out of the default setting, they will end up choosing the preselected option. Just like other nudges, defaults have been applied to many behavioral domains such as organ donation (Johnson \& Goldstein, 2003), financial behavior (Madrian \& Shea, 2001), and sustainable behavior (e.g., Pichert \& Katsikopoulos, 2008). Default effects are typically robust with an average effect size of $d=$ .68 (Jachimowicz et al., 2019), although it should be noted that there can be quite some variation $(95 \% \mathrm{Cl}=0.53-0.83)$, as for example defaults are generally found to be more effective in consumer domains than in environmental domains. The notion that even such strong nudges like defaults do not always work for everyone suggests that other factors such as motivation may impact behavior apart from the default nudge.

\section{The role of motivation}

Nudges are often suggested as a helpful tool to promote behavior that people are assumed to be motivated for, in the sense that it is either beneficial for themselves (pro-self nudges; e.g., healthy eating) or for society at large (pro-social nudges; e.g., sustainable choices). In fact, there should at least be some kind of motivation for a nudge to be 
legitimate (Bovens, 2009). Thaler and Sunstein (2008) also highlight this in their 'nudge for good' principle: policy makers ought to have beneficent intentions and a nudge should only be effective if individuals at least have a minimum motivation to perform the behavior the nudge is aimed at. As a consequence, one could argue that the intention of the nudge should be reflected in an individual's motivation to perform that behavior. But whether this principle upholds in practice, or whether it is no more than a noble endeavor, is yet to be studied empirically. To be more precise, whether motivation moderates nudge effectiveness and thus forms a boundary condition is still an open question. Moreover, whether this effect differs for motivation which reflects personal interests and values (i.e., autonomous motivation) as opposed to caused by external or internal pressures (i.e., controlled motivation) is still to be determined. Finally, an important question that remains to be studied is whether nudges do in fact facilitate desired behavior when accounting for individual's motivation.

To date, research that explicitly addresses the role of motivation in the context of nudges' effectiveness is lacking. We are also not aware of any studies that looked at proximal predictors of motivation such as needs. However, some research has been done to examine the impact of attitudes on nudge effectiveness, mostly in the realm of sustainable behavior (e.g., green electricity uptake or organic food choices). These studies have consistently revealed that default nudges and attitudes independently predict behavioral outcomes (Kaiser et al., 2020; Kuhn et al., 2020; Taube \& Vetter, 2019; Vetter \& Kutzner, 2016). Thus, current evidence suggests that defaults and attitudes have distinct and independent effects on behavior.

Another construct that is related to motivation - preferences - has been given attention both in rather generic claims and empirical research. It has, for example, been 
stated that "if preferences [...] are strong, we would expect defaults to have little or no effect" (Johnson \& Goldstein, 2003, p. 1339). Similarly, it has been suggested that "wellformed preferences [...] trump default rules" (Sunstein \& Thaler, 2003, p. 1198). Findings from experimental studies in the realm of nudging healthy behavior suggest that specific a priori preferences such as liking for soft drinks or preferences for meat can affect behavioral outcomes apart from nudges' effectiveness (Venema et al., 2020; Venema et al., 2019). Still, the remaining question is what happens to someone who does not necessarily have such specific preferences (for or against sugar sweetened beverages or meat), but does have an overarching motivation to live healthily or sustainably.

Together, these studies on attitudes and a priori preferences imply that nudges may add a propensity to choose a certain option that builds on existing attitudes and preferences. However, a direct test of motivational tendencies, rather than related constructs, is still required. To address this, we focus on a generic measure of motivation strength (goal strivings) to measure what people are trying to achieve, as well as on different types of motivation such as autonomous motivation, controlled motivation, and amotivation (Deci \& Ryan, 2000) to measure why people are trying to achieve this. Autonomous motivation is a type of goal striving that is at least to some extent internalized such that autonomously motivated behavior is self-endorsed and performed out of interest or personal value. Controlled motivation is a type of goal striving that is pressured by forces of control. Behavior that results from controlled motivation is at least to some extent driven by internally or externally imposed forces such as reward, punishment or social approval. Still, both types of motivation represent intentionally caused actions, which is in contrast with amotivation. Amotivation describes a lack of intention or motivation to act, and often results in inaction. How these different types of motivation relate to nudges' effectiveness bears 
implications for the meaning of 'nudge for good': whether it is for the greater good, related to external pressures, or originating from intrinsic needs.

\section{The Current Studies}

To study the role of motivation in nudging effectiveness, we conducted three experiments across different behavioral domains (pro-self and pro-social) with different types of default nudges. In all three studies, the default nudge stimulated rather undisputed behaviors, inspired by the 'nudge for good' principle (Thaler \& Sunstein, 2008). In Study 1, we embedded a default nudge in a hypothetical online supermarket task to stimulate healthier food choices. This default was continuously presented over a series of repeated choices with three alternative options in the choice task. In Study 2, we used a default nudge in a scenario in order to stimulate sustainable choices. This default was applied to a list of options in which all of the options were preselected or not at the same time. In Study 3, we used a default nudge in a real choice situation in which participation in a longer study on sustainability was stimulated. This default was applied to the desirable option in a set of two options that were presented at the same time. Across these three studies, we measured different motivational constructs in order to increase generalizability of our results: a rather generic measure of motivation strength (goal strivings), as well as autonomous motivation, controlled motivation and amotivation. Similarly, we focused on different kinds of behavior to increase external validity.

All three studies were preregistered on AsPredicted.org. In Study 1, we preregistered the hypothesis that the default nudge would be effective in stimulating healthier food choices, and indicated to explore the role of motivation (without preregistering specific hypotheses for that; https://aspredicted.org/jh62s.pdf). In Study 2, we again preregistered the hypothesis that the default nudge would be effective, but based on results from Study 1 , 
we now also preregistered the hypothesis that autonomous motivation and goal strivings would have a main effect as well. We did not expect a main effect for controlled motivation, nor an interaction effect between the nudge and any of the motivation constructs (https://aspredicted.org/45q7n.pdf). Finally, in Study 3 we preregistered the same hypotheses for autonomous motivation and goal strivings as in Study 2, but based on results from Study 1 and 2, this time we left two possibilities open for controlled motivation (either or not a main effect). We again did not expect to find interaction effects (https://aspredicted.org/8hv2x.pdf).

\section{Study 1}

\section{Method}

Participants and Design. We conducted a power analysis for detecting a statistically meaningful effect of the default nudge with an independent samples t-test (one-tailed). We did not have any previous studies to base an effect size on and wanted to be conservative for this first study. Therefore, we set the minimum effect size of interest at $d=0.2$, and used $\alpha=.05$ and $\beta=.80$, which resulted in a minimum required sample size of 620 participants.

We recruited 635 participants (454 female, 178 male, 1 Other/Rather not specify, 2 missing; $M_{\text {age }}=34.93, S D_{\text {age }}=12.60^{1}$ ) from Prolific Academic. We included adult participants with a UK nationality and a minimum approval rate of 95\%. Participants were rewarded with $£ 0.50$ for their participation. We used a one factor (Condition: control vs. default) betweensubjects design with the proportion of nudged healthy products chosen as dependent variable. The study was approved by the Ethics Committee of the Faculty of Social and Behavioral Sciences of Utrecht University under number 18-046.

\footnotetext{
${ }^{1}$ Due a technical error, 2 participants did not fill in the demographics questionnaire at the end of the study. All demographics that are reported are based on $N=633$.
} 
Procedure. Participants were invited to participate in an online supermarket study. After they provided active informed consent, we administered two questionnaires (Treatment Self-Regulation Questionnaire (TSRQ) and a bogus lifestyle questionnaire with goal striving items embedded). Next, participants entered our online supermarket. Participants were randomly allocated to the control or default condition and went through 14 different trials in which they were instructed to choose 1 out of a set of 4 products. After completing the supermarket task, we asked participants for their demographics and a few other measures. Finally, participants were debriefed, thanked and paid for their participation.

\section{Materials.}

Online supermarket task. In the online supermarket task, participants were instructed to select a food product to add to their online grocery basket. The task consisted of 14 trials, of which 4 were filler trials. In each trial, participants saw four food products. All stimuli were pilot tested $(N=60)$ for perceived healthiness and tastiness, and were combined in such a way that each relevant trial consisted of four products within the same food category (e.g., crisps or jam) of which two were considered to be healthier but less tasty than the other two products. The four filler trials included only healthier (e.g., vegetables only) or unhealthier products (e.g., sugar-sweetened beverages only), and did thus not include a trade-off between the options. All images were surrounded by a light grey box, which would turn black upon selection of the product. Participants could select their preferred product by clicking on the image and could continue to the next trial by clicking 'Add to basket', thereby confirming their decision. In the control condition, the four products were presented in a 2 by 2 matrix, with all pictures presented in equal size. In the default condition, one of the healthier products was preselected such that it already had a 
black box around the image and was made more salient by presenting the image in a larger size above the other three products (See Figure 1). Thus, sticking with the default would require clicking 'Add to basket' only, while changing away from the default would require a similar amount of effort as choosing a product in the control condition (one click to select a product plus one click to add it to the basket). Which of the two healthier products was preselected was counterbalanced across participants. We counted the number of times that participants chose the product of interest (the nudged healthy product) over the ten relevant trials, and combined these counts in a proportion score, which served as the main dependent variable for this study. Higher scores represent a higher likelihood of choosing the nudged healthy product.

Figure 1. Example trial of online supermarket task in the control condition (left) and default condition (right). We obtained permission to reproduce the pictures from Tesco PLC.

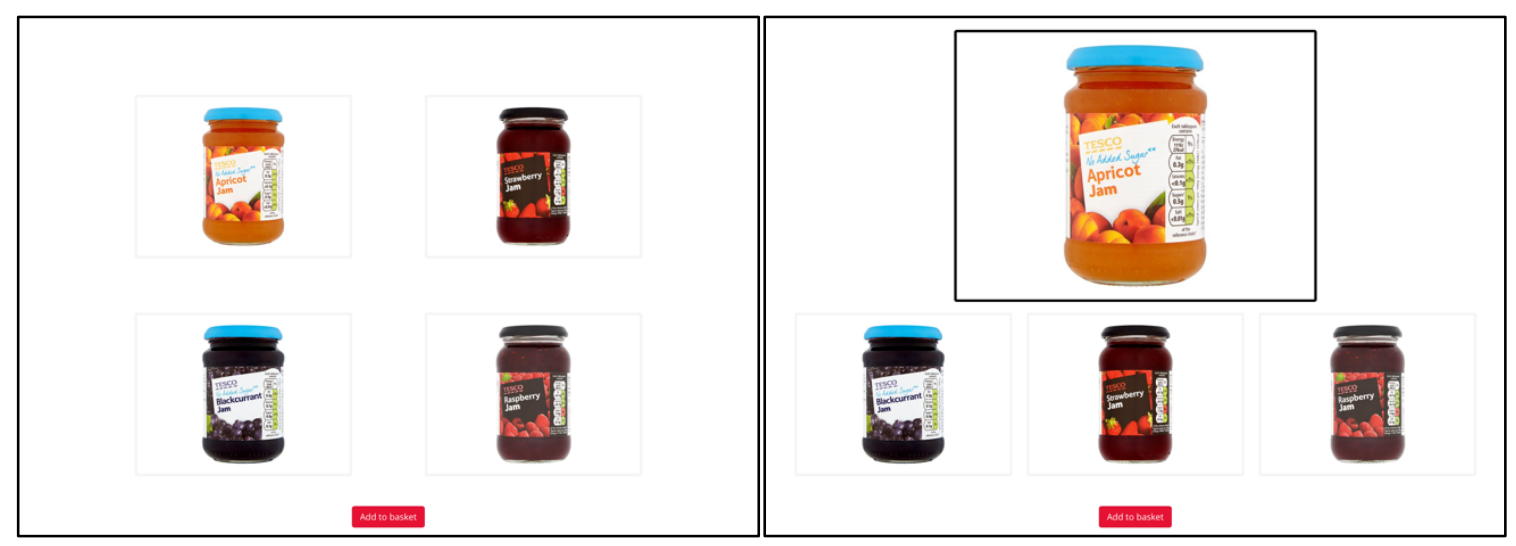

Measures.

Treatment Self-Regulation Questionnaire. In order to measure autonomous motivation, controlled motivation, and amotivation, we administered the TSRQ (Levesque et al., 2007). The questionnaire consisted of fifteen statements that provided possible reasons for eating a healthy diet (e.g., 'Because I feel that I want to take responsibility for my own 
health' (Autonomous motivation; 6 items), 'Because I feel pressure from others to do so' (Controlled motivation; 6 items), and 'I really don't think about it' (Amotivation; 3 items)). All statements were measured on a 7-point Likert scale, ranging from 1 (not at all true) to 7 (very true). Composite scores were created by averaging the items that belonged to each subscale. The subscales for autonomous motivation (Cronbach's $\alpha=.86$ ) and controlled motivation (Cronbach's $\alpha=.82$ ) showed good reliability, while the subscale for amotivation (Cronbach's $\alpha=.56$ ) showed to have poor reliability.

Goal strivings. As an additional measure of motivation, we administered a bogus lifestyle questionnaire which included four items based on research on personal strivings (Emmons, 1986). These goal strivings represent what a person is characteristically trying to do or accomplish with their behavior and we used this as a measure of motivation strength. We administered the four items for the behavior of interest (healthy eating) as well as for two unrelated behaviors (sustainable behavior and saving money). The four items measured commitment ("How committed are you to eating healthily?"), importance ("How important is eating healthily to you in your life?"), and value ("How much joy or happiness do you or will you feel when you are successful in eating healthily?" and "How much sorrow or unhappiness do you or will you feel if you fail to succeed in eating healthily?"). All questions were asked on a 7-point Likert scale, ranging from 1 (not at all) to 7 (very much). The measure had acceptable internal reliability (Cronbach's $\alpha=.77)$, and thus all items were combined into one score by averaging the four items.

Demographics. We asked participants for their age (in years) and gender (female, male, other/rather not specify). We also asked how hungry and thirsty participants were at that moment, using two questions with a 7-point Likert scale, ranging from 1 (not hungry/thirsty at all) to 7 (very hungry/thirsty). Finally, we asked for participants' weight, 
which they could enter in their preferred measurement unit (stones and pounds or kilograms), and height (feet and inches or meters and centimeters). From these measurements, we calculated participants' BMI.

\section{Results}

Data are available on the Open Science Framework (https://osf.io/javhx/).

Preprocessing steps. As preregistered, outliers (defined as 3 SDs away from the mean) were set missing for the most important variables: proportion of nudged healthy choices (5 participants), autonomous motivation (5 participants), amotivation (1 participant) and goal strivings (9 participants). All analyses were run with inclusion and exclusion of outliers, but this did not change any of the results (i.e., direction or significance of effects). Therefore, we report on the entire sample with inclusion of outliers.

Descriptives. On average, participants scored moderately high on the measure of goal strivings for eating healthily $(M=4.95, S D=1.14)$. Especially autonomous motivation was high $(M=5.53, S D=1.02)$, while controlled motivation was slightly below the midpoint $(M=3.31, S D=1.23)$. Amotivation was relatively low $(M=2.47, S D=1.11)$. See Table $A 1$ in Appendix A for a full overview of the descriptives and correlation coefficients.

Randomization check. In order to check whether randomization of participants across the two conditions was successful, we ran separate independent samples t-tests with condition (control vs. default) as independent variable and age, hunger, thirst, BMI, goal strivings, autonomous motivation, controlled motivation, and amotivation as continuous dependent variables. For gender, we ran a Chi-squared analysis. Results showed that randomization was successful (all ps > .182).

Main analyses. We ran a pre-registered one-tailed independent samples t-test to analyze the effect of the default nudge on the proportion of nudged healthy choices. The 
default nudge had a small to medium effect, $t(633)=-4.33, p<.001, d=.34,95 \% \mathrm{Cl}[$-inf; $.04]$, such that participants chose more healthy nudged products in the default condition ( $M$ $=.33, S D=.21)$ than in the control condition $(M=.27, S D=.17)$.

In order to analyze whether motivation moderates nudge effectiveness, we ran four separate hierarchical multiple regressions. In step 1, we created our base model by including the main effect of the default nudge (with the control condition coded as 0 and the default condition coded as 1 ). In step 2, we added the main effect of motivation (goal strivings, autonomous motivation, controlled motivation, and amotivation respectively). In step 3, we added the interaction term between the default nudge and motivation (See Table 1 for the complete regression results). Not surprisingly, the default nudge turned out significant in our regression models as well $\left(\beta=.17, p<.001, R_{a d j}{ }^{2}=0.03\right)$. Adding goal strivings to the base model improved model fit $\left(\operatorname{Radj}^{2}=0.09, p<.001\right)$, and goal strivings for eating healthily significantly predicted the proportion of nudged healthy choices $(\beta=.25, p<.001)$. Similarly, adding autonomous motivation to the base model improved model fit $\left(\operatorname{Radj}^{2}=0.08, p<.001\right)$, and autonomous motivation for eating healthy diets significantly predicted the proportion of nudged healthy choices $(\beta=.24, p<.001)$. Adding the controlled motivation to the base model did not improve model fit $(p=.193)$. Adding amotivation to the base model improved model fit $\left(\operatorname{Radj}^{2}=0.10, p<.001\right)$, and amotivation for eating healthy diets significantly predicted the proportion of nudged healthy choices $(\beta=-.28, p<.001)$. Adding interaction terms did not improve model fit for any of the motivational constructs (all $p s>.545$ ).

Table 1. Regression model with the proportion of nudged healthy food choices as dependent variable (Study 1).

\begin{tabular}{lcccccr}
\hline & $\Delta R_{a d j^{2}}$ & $b(S E)$ & $\beta$ & $95 \% \mathrm{Cl} b$ & $t$ & $p$ \\
\hline Step 1 & 0.03 & & & & $<.001$
\end{tabular}




\begin{tabular}{|c|c|c|c|c|c|c|}
\hline Constant & & $0.26(0.01)$ & & {$[0.24,0.29]$} & 24.41 & $<.001$ \\
\hline Default & & $0.07(0.02)$ & 0.17 & {$[0.04,0.10]$} & 4.33 & $<.001$ \\
\hline Step $2-$ Goal strivings & 0.06 & & & & & $<.001$ \\
\hline Constant & & $0.05(0.03)$ & & {$[-0.02,0.12]$} & 1.50 & .133 \\
\hline Default & & $0.07(0.01)$ & 0.17 & {$[0.04,0.10]$} & 4.49 & $<.001$ \\
\hline Goal strivings & & $0.04(0.01)$ & 0.25 & {$[0.03,0.06]$} & 6.63 & $<.001$ \\
\hline $\begin{array}{l}\text { Step } 2 \text { - Autonomous } \\
\text { motivation }\end{array}$ & 0.05 & & & & & $<.001$ \\
\hline Constant & & $0.02(0.04)$ & & {$[-0.06,0.10]$} & 0.47 & .641 \\
\hline Default & & $0.06(0.01)$ & 0.16 & {$[0.03,0.09]$} & 4.12 & $<.001$ \\
\hline Autonomous motivation & & $0.04(0.01)$ & 0.24 & {$[0.03,0.06]$} & 6.17 & $<.001$ \\
\hline $\begin{array}{l}\text { Step } 2 \text {-Controlled } \\
\text { motivation }\end{array}$ & 0.00 & & & & & .193 \\
\hline Step 2 - Amotivation & 0.07 & & & & & $<.001$ \\
\hline Constant & & $0.42(0.02)$ & & {$[0.38,0.45]$} & 23.30 & $<.001$ \\
\hline Default & & $0.04(0.01)$ & 0.18 & {$[0.02,0.05]$} & 4.78 & $<.001$ \\
\hline Amotivation & & $-0.05(0.01)$ & -0.28 & {$[-0.06,-0.04]$} & -7.32 & $<.001$ \\
\hline
\end{tabular}

Note. $\beta$ s are fully standardized. $N=635$.

In order to analyze whether the default adds an increased propensity of choosing the desired option, we also ran stepwise regressions starting with motivation in step 1 and adding the condition variable in step 2 . These analyses consistently revealed that the default predicted healthy food choices when accounting for motivation with small but significant improvements in model fit ranging from 0.02 to 0.03 (See Online Supplementary Materials for full details).

\section{Discussion Study 1}

In Study 1, we found that the default nudge had a significant effect on the number of nudged healthy choices in an online supermarket setting. This illustrates that nudges can 
successfully be implemented in online choice settings, which is in line with current evidence (Antonides \& Welvaarts, 2020; Coffino et al., 2020; Kuhn et al., 2020). Moreover, we found that goal strivings and autonomous motivation also had a positive main effect on the number of nudged healthy choices. We did not find an effect of controlled motivation, nor did we find any significant interaction patterns. Finally, we found a significant negative effect of amotivation on the number of nudged healthy choices, even though it should be noted that amotivation had poor reliability. Generally, motivation to eat healthily was rather high, especially autonomous motivation, which corresponds with the idea that this was a pro-self nudge that was in line with people's own motivation.

The goal of Study 2 was to replicate these findings with another kind of default nudge and within another behavioral domain. In Study 1 the default was repeatedly implemented over different trials and nudged one out of four products. In Study 2 the default was applied to a list of options in which all of the options were preselected or not at the same time. We also wanted to test the robustness of our effects within the domain of sustainable choices, which arguably is more of a pro-social domain and a domain where we expected slightly more variance in motivation. We hypothesized that the default nudge would be effective in stimulating sustainable choices, and that autonomous motivation and goal strivings would also have a positive main effect. In line with Study 1, we did not expect to find a significant effect of controlled motivation and we did not expect to find any interaction effect.

\section{Study 2}

\section{Method}

Participants and Design. In Study 2, we were particularly interested in the role of motivation, and based on the correlations between the motivation measures and the dependent variable in Study 1, we defined the smallest effect size of interest as small. 
Therefore, we conducted a power analysis in G*Power for a linear multiple regression with 2 predictors and a minimum effect size of interest of $f^{2}=.02$ (small), and used $\alpha=.05$ and $\beta=$ .80. This resulted in a minimum required sample size of 485 . In order to be able to exclude participants who failed the attention checks, we oversampled with $10 \%$, resulting in a desired sample size of 534 .

We collected data on Prolific Academic from 535 participants. One participant failed two attention checks and was, according to our preregistration, excluded from further analyses. This resulted in a final sample size of 534 participants (333 female, 197 male, 4 Other/Rather not specify; $\left.M_{\text {age }}=35.05, S D_{\text {age }}=13.02\right)$. We used the same inclusion criteria as in Study 1 and participants were rewarded with $£ 0.70$ for their participation. We used a one factor (Condition: control vs. default) between-subjects design with the number of green amenities chosen as dependent variable. The study was approved by the Ethics Committee of the Faculty of Social and Behavioral Sciences of Utrecht University under number 20-378.

Procedure. Participants were invited to participate in a study on lifestyle and decision making. After they provided active informed consent, we administered two questionnaires (TSRQ and a bogus lifestyle questionnaire with goal striving items embedded). Next, participants read a scenario and were asked to choose the green amenities that they would like to have. In this amenity selection task, participants were randomly allocated to the control or default condition. After that, we asked participants for satisfaction with their choice. For exploratory purposes (i.e., to explore whether the nudged behavior would alter motivation), we administered the same two questionnaires (TSRQ and lifestyle) again. Finally, we asked participants for their demographics, queried for suspicion of the goal of the study and ended with an open question in which participants could write anything they 
deemed relevant. Finally, participants were debriefed, thanked and paid for their participation.

\section{Materials.}

Amenity selection task. To measure the effectiveness of the default nudge to stimulate sustainable choices, we used a scenario in which participants had to imagine that they had just decided to rent a newly constructed apartment (Steffel et al., 2016). They read that, before signing the rental contract, the landlord offered them a list of 14 optional green amenities. In the control condition, none of the amenities were preselected and were thus not included in the rent. They could actively choose to select certain amenities from the list for an additional monthly price, ranging from $£ 2$ to $£ 8$ for each amenity chosen. In the default condition, all amenities were preselected and were included in the rent. Participants could unselect certain amenities from the list, such that the landlord would deduct a small amount of money from the monthly rent (again, ranging from $f 2$ to $f 8$ ). There was thus no pricing difference between the two conditions. We used the same list of amenities as in Van Gestel and colleagues (2020a), and measured the number of green amenities selected by the participants. This variable ranged from 0 to $14 .^{2}$

\section{Measures.}

Treatment Self-Regulation Questionnaire. We again used the TSRQ to measure autonomous motivation, controlled motivation, and amotivation. Participants rated the same 15 items, although some items needed to be slightly rephrased in order to match the behavior of making sustainable choices. All statements were again measured on a 7-point Likert scale, ranging from 1 (not at all true) to 7 (very true). Similar to Study 1, composite

\footnotetext{
${ }^{2}$ After the amenity selection task, we asked participants how satisfied they were with their choice with 1 item ("How satisfied are you with the amenities that you chose?") measured on a 7-point Likert scale ranging from 1 (not at all) to 7 (very much; See Online Supplemental Material).
} 
scores were created by averaging the items that belonged to each subscale. The subscales for autonomous motivation (Cronbach's $\alpha=.93$ ) and controlled motivation (Cronbach's $\alpha=$ .81) showed good reliability, while the subscale for amotivation (Cronbach's $\alpha=.67$ ) showed to have questionable reliability. We had initially preregistered to not analyze the amotivation construct. $^{3}$

Goal strivings. We included the same lifestyle questionnaire as in Study 1. This time the four items of interest were focused on the behavior of making sustainable choices. All questions were asked on a 7-point Likert scale, ranging from 1 (not at all) to 7 (very much). The filler items about eating healthily and saving money were not analyzed and were solely included to conceal the goal of the study. The measure had good internal reliability (Cronbach's $\alpha=.87$ ), and thus all items were combined into one score by averaging the four items.

Demographics. We asked participants for their age (in years) and gender (female, male, other/rather not specify). Further, we queried for suspicion of the goal of the study with one open-ended question ("What do you think was the goal of this study?"), and with a final open-ended question in which participants could answer any final thoughts.

\section{Results}

Data are available on the Open Science Framework (https://osf.io/bj5kc/).

Preprocessing steps. One participant failed both attention checks and was excluded from all analyses. Outliers were defined as 3 SDs away from the mean and were set missing for the most important variables. This only applied to controlled motivation (1 participant) and amotivation (1 participant). All analyses were run with inclusion and exclusion of these

\footnotetext{
${ }^{3}$ For exploratory purposes, we administered the same questionnaire again after participants had chosen the green amenities. These exploratory analyses did not yield any noteworthy results and thus these data are not reported.
} 
outlier, but this did not change any of the results (i.e., direction or significance of effects). Therefore, we report on the entire sample with inclusion of outliers.

Descriptives. On average, participants scored moderately high on the measure of goal strivings for making sustainable choices $(M=4.65, S D=1.22)$. Autonomous motivation was highest $(M=4.87, S D=1.34)$, while controlled motivation was slightly below the midpoint $(M=3.33, S D=1.14)$. Amotivation was relatively low $(M=2.70, S D=1.26)$. See Table A2 in Appendix A for a full overview of the descriptives and correlation coefficients.

Randomization check. We performed the same analyses as in Study 1 to check for randomization of participants across the two conditions, this time with age, gender, goal strivings, autonomous motivation, controlled motivation, and amotivation as dependent variables. Results showed that randomization was successful (all $p s>.142$ ).

Main analyses. We ran a two-tailed independent samples t-test to analyze the effect of the default nudge on the number of green amenities. The default nudge had a large effect, $t(532)=-24.59, p<.001, d=2.13,95 \% \mathrm{Cl}[-5.93 ;-5.06]$, such that participants chose more green amenities in the default condition $(M=11.65, S D=2.56)$ than in the control condition $(M=6.15, S D=2.60)$.

In order to analyze whether motivation moderates nudge effectiveness, we conducted the same separate hierarchical multiple regressions as in Study 1, starting with the default nudge in step 1 (with the control condition coded as 0 and the default condition coded as 1), the motivation measures in step 2, and the interaction effect in step 3 (See Table 2 for the complete regression results). Not surprisingly, the default nudge turned out significant in our regression models as well $\left(\beta=.73, p<.001, R_{a d j}{ }^{2}=0.53\right)$. Adding goal strivings to the base model improved model fit $\left(R_{a d j}{ }^{2}=0.56, p<.001\right)$, and goal strivings for making sustainable choices significantly predicted the number of green amenities $(\beta=.16, p$ 
$<$.001). Similarly, adding autonomous motivation to the base model improved model fit $\left(R_{a d j}{ }^{2}=0.58, p<.001\right)$, and autonomous motivation for making sustainable choices significantly predicted the number of green amenities $(\beta=.22, p<.001)$. Unexpectedly, adding controlled motivation to the base model also improved model fit $\left(R_{a d j}{ }^{2}=0.54, p=\right.$ .014), but the improvement in model fit was negligible $\left(\Delta R_{a d j}{ }^{2}=.00\right)$. Controlled motivation for making sustainable choices significantly predicted the number of green amenities ( $\beta=$ $.07, p=.014)$. Adding interaction terms did not improve model fit for any of the motivational constructs (all ps > .214).

Table 2. Regression model with the number of green amenities as dependent variable (Study 2).

\begin{tabular}{|c|c|c|c|c|c|c|}
\hline & $\Delta R_{a d j}^{2}$ & $b(S E)$ & $\beta$ & $95 \% \mathrm{Cl} b$ & $t$ & $p$ \\
\hline Step 1 & 0.53 & & & & & $<.001$ \\
\hline Constant & & $6.15(0.16)$ & 0.73 & {$[5.84,6.46]$} & 38.85 & $<.001$ \\
\hline Default & & $5.50(0.22)$ & & {$[5.06,5.93]$} & 24.59 & $<.001$ \\
\hline Step 2 - Goal strivings & 0.03 & & & & & $<.001$ \\
\hline Constant & & $3.81(0.45)$ & & {$[2.94,4.69]$} & 8.54 & $<.001$ \\
\hline Default & & $5.54(0.22)$ & 0.74 & {$[5.11,5.97]$} & 25.46 & $<.001$ \\
\hline Goal strivings & & $0.50(0.09)$ & 0.16 & {$[0.32,0.67]$} & 5.57 & $<.001$ \\
\hline $\begin{array}{l}\text { Step } 2 \text { - Autonomous } \\
\text { motivation }\end{array}$ & 0.05 & & & & & $<.001$ \\
\hline Constant & & $3.08(0.41)$ & & {$[2.27,3.89]$} & 7.47 & $<.001$ \\
\hline Default & & $5.48(0.21)$ & 0.73 & {$[5.06,5.89]$} & 25.91 & $<.001$ \\
\hline $\begin{array}{l}\text { Autonomous } \\
\text { motivation }\end{array}$ & & $0.63(0.08)$ & 0.22 & {$[0.48,0.79]$} & 7.98 & $<.001$ \\
\hline $\begin{array}{l}\text { Step } 2 \text { - Controlled } \\
\text { motivation }\end{array}$ & 0.00 & & & & & .014 \\
\hline Constant & & $5.35(0.36)$ & & {$[4.64,6.06]$} & 14.84 & $<.001$ \\
\hline
\end{tabular}




\begin{tabular}{lrrrrrr} 
Default & $5.50(0.22)$ & 0.73 & {$[5.06,5.93]$} & 24.71 & $<.001$ \\
$\quad$ Controlled motivation & & $0.24(0.10)$ & 0.07 & {$[0.05,0.43]$} & 2.46 & .014 \\
$\begin{array}{l}\text { Step 2-Amotivation } \\
\text { Constant }\end{array}$ & 0.02 & & & & & $<.001$ \\
Default & & $7.26(0.29)$ & & {$[6.70,7.82]$} & 25.37 & $<.001$ \\
Amotivation & $5.45(0.22)$ & 0.72 & {$[5.02,5.88]$} & 24.84 & $<.001$ \\
& $-0.40(0.09)$ & -0.13 & {$[-0.57,-0.23]$} & -4.62 & $<.001$ \\
\hline
\end{tabular}

Note. $\beta$ s are fully standardized. $N=534$.

Exploratory analyses. In addition to our preregistration, we decided to explore results with amotivation in the regression models as well. Adding amotivation to the base model improved model fit $\left(R_{a d j}{ }^{2}=0.55, p<.001\right)$, and amotivation for making sustainable choices significantly predicted the number of green amenities $(\beta=-.13, p<.001)$.

In order to analyze whether the default adds an increased propensity of choosing the desired option, we also ran stepwise regressions starting with motivation in step 1 and adding the condition variable in step 2 . These analyses consistently revealed that the default predicted the number of green amenities when accounting for motivation with large significant improvements in model fit ranging from 0.52 to 0.54 (See Online Supplementary Materials for full details).

\section{Discussion Study 2}

In Study 2, we found that the default nudge had a significant effect on the number of green amenities chosen, and that goal strivings and autonomous motivation also had a positive main effect. Unexpectedly, we also found a main effect for controlled motivation, although with a smaller effect size than the other motivational constructs. Finally, amotivation again had a significant negative effect on the number of green amenities chosen. No significant interaction effects were found. Compared to Study 1, scores for autonomous motivation and goal strivings were slightly lower, but still only few participants 
scored below the midpoint of the scales ( $21 \%$ and $23 \%$, respectively). In Study 2, we thus conceptually replicated the results from Study 1 , but this time in a prosocial domain, and with a stronger impact of the default nudge on choice outcomes when accounting for motivation.

In Study 3, we wanted to extend our findings to a context where the choice would have actual direct implications for the person making the choice. Therefore, we used a default manipulation which preselected the option to voluntarily participate in a longer version of a study on sustainability. In contrast to Study 1 and 2, this choice would therefore have immediate behavioral consequences. Besides, the operationalization of the default nudge was different than in previous studies, as this time only one decision would be required in which the desirable and alternative option were presented simultaneously. Also, the desirable behavior could be seen as an act of prosocial behavior, as participation in the longer version would be voluntarily and helpful for the researchers. To address this, we measured goal strivings, autonomous motivation, controlled motivation, and amotivation to help other people. In line with findings from Study 1 and 2, we hypothesized that goal strivings and autonomous motivation would have a main effect on participation in the longer version. For controlled motivation, we did not have a specific a priori hypothesis as results thus far were mixed. In line with Study 1 and 2, we also did not hypothesize any interaction effects. In addition to measuring motivational constructs related to helping, we also assessed the same motivational constructs related to the alleged context of the study, which was sustainable behavior. We did not have any a priori hypotheses for these measures.

\section{Study 3}

\section{Method}


Participants and design. In Study 3, we were again interested in the role of motivation, and based on the correlations between the motivation measures and the dependent variables in Study 1 and 2, we defined the smallest effect size of interest as small. Therefore, we conducted a power analysis in G*power for a logistic regression with a minimum effect size of interest of $O R=1.3$ (small), and used $\alpha=0.05, \beta=.80, \operatorname{Pr}(Y=1 \mid X=1)$ $H O=.5$, and $R^{2}$ other $X=.13$ (medium). This resulted in a minimum required sample size of 544. Since we only had to exclude one participant who failed our attention checks in Study 2, we decided to not oversample.

In this study, none of the participants failed both attention checks and thus no participants were excluded from further analyses. This resulted in a final sample size of 544 participants (332 female, 209 male, 3 Other/Rather not specify; $M_{\text {age }}=34.83, S D_{\text {age }}=12.94$ ). We again recruited from Prolific Academic and used the same inclusion criteria as in Study 1 and 2. Participants were rewarded with $£ 1.20$ for their participation, ostensibly with $£ 0.50$ for the first study and $£ 0.70$ for the second study (flat fee). We used a one factor (Condition: control vs. default) between-subjects design with participation in the longer version of our study as dependent variable. The study was approved by the Ethics Committee of the Faculty of Social and Behavioral Sciences of Utrecht University under number 20-395.

Procedure. Participants were invited to participate in two ostensibly unrelated studies. One study would concern lifestyle and the other would concern sustainability. After they provided active informed consent, participants started the first study on Gorilla (AnwylIrvine et al., 2020) with the TSRQ, which we administered for the primary behavior of interest (helping other people), the secondary behavior of interest (making sustainable choices) as well as for one filler behavior (healthy eating). After that participants filled in a bogus lifestyle questionnaire with items on goal strivings for helping other people and 
making sustainable choices, as well as with filler items on healthy eating and saving money.

After that, we used a fake debriefing to ostensibly end the first study and redirected participants to another platform (Qualtrics) for the second study. This was done in order to enhance the cover story of two separate studies. The second study started with informed consent and by asking participants whether they would be willing to participate in a longer version of the questionnaire of this second study. After that, we asked participants for satisfaction with their choice, about acceptability of the default nudge, and for their demographics. Finally, participants were debriefed, thanked and paid for their participation.

\section{Materials.}

Study choice task. Based on Wachner and colleagues (2020), we asked participants if they wanted to participate in a basic or a longer version of our second study, which would ostensibly be about sustainability. The basic version was estimated to last about 7 minutes, and the longer version would take an additional 5 minutes. Participants were told that they would not be compensated for their extra efforts, but that it would help researchers in improving their future questionnaires. This was done in order to communicate the prosocial nature of this decision. ${ }^{4}$

\section{Measures.}

Treatment Self-Regulation Questionnaire. We again used the TSRQ to measure autonomous motivation, controlled motivation, and amotivation. Participants rated the

\footnotetext{
${ }^{4}$ Immediately after participants had decided to participate in the basic or longer questionnaire, we measured satisfaction with their choice with 1 item ("How satisfied are you with your decision?"), measured on a 7-point Likert scale ranging from 1 (not at all) to 7 (very much). After that, we asked about acceptability and intrusiveness of the question to participate in a longer version and the way the options were presented. In the default condition, we explicitly mentioned that one option was preselected. We used four items on a 7-point Likert scale, ranging from 1 (not at all) to 7 (very much): "How acceptable do you find this question?", "How intrusive do you find this question?", "How acceptable do you find this way of presenting the options?", and "How intrusive do you find this way of presenting the options?" (See Online Supplemental Material).
} 
same 15 items, although some items needed to be slightly rephrased in order to match the behavior of helping other people. All statements were again measured on a 7-point Likert scale, ranging from 1 (not at all true) to 7 (very true). Composite scores were created by averaging the items that belonged to each subscale. The subscales for autonomous motivation (Cronbach's $\alpha=.84$ ) and controlled motivation (Cronbach's $\alpha=.80$ ) showed good reliability, while the subscale for amotivation (Cronbach's $\alpha=.58$ ) showed to have poor reliability. Again, we had initially preregistered to not analyze the amotivation construct. In order to enhance the strength of our cover story that this first study was about lifestyle, we also administered the TSRQ on healthy eating and making sustainable choices. Administration of the TRSQ for making sustainable choices simultaneously allowed us to explore those motivational constructs, as this would be related to the topic of the second study (sustainability). The subscales for autonomous motivation (Cronbach's $\alpha=.93$ ) and controlled motivation (Cronbach's $\alpha=.79$ ) showed good reliability, while the subscale for amotivation (Cronbach's $\alpha=.68$ ) showed to have questionable reliability.

Goal strivings. We included the same lifestyle questionnaire as in Study 1 and 2. This time the four items of interest were focused on the behavior of helping other people. All questions were asked on a 7-point Likert scale, ranging from 1 (not at all) to 7 (very much). We also administered goal strivings for making sustainable choices, as this was related to the topic of the second study. The filler items about eating healthily and saving money were not analyzed and were solely included to conceal the goal of the study. The measure for goal strivings for helping other people had good internal reliability (Cronbach's $\alpha=.81$ ), and thus all items were combined into one score by averaging the four items. This was also done for the items for making sustainable choices, as this also revealed to have good internal reliability (Cronbach's $\alpha=.88$ ). 
Demographics. We asked participants for their age (in years) and gender (female, male, other/rather not specify).

\section{Results}

Data are available on the Open Science Framework (https://osf.io/7w4vf/).

Preprocessing steps. No participants failed both attention checks and thus no participants were excluded from the analyses. Outliers were defined as 3 SDs away from the mean and were set missing for the most important variables. This applied to our measures of autonomous motivation (5 participants), amotivation (4 participants) and goal strivings (4 participants). All analyses were run with inclusion and exclusion of these outliers, but this did not change any of the results (i.e., direction or significance of effects). Therefore, we report on the entire sample with inclusion of outliers.

Descriptives. On average, participants scored high on the measure of goal strivings for helping other people $(M=5.37, S D=1.07)$. Autonomous motivation was highest $(M=$ $5.26, S D=1.08)$, while controlled motivation was slightly below the midpoint $(M=3.78, S D=$ 1.18). Amotivation was relatively low $(M=2.33, S D=1.09)$. See Table $A 3$ in Appendix $A$ for a full overview of the descriptives and correlation coefficients.

Regarding the motivation to make sustainable choices, participants scored moderately high on the measure of goal strivings $(M=4.66, S D=1.31)$. Especially autonomous motivation was high $(M=5.30, S D=1.33)$, while controlled motivation was slightly below the midpoint $(M=3.61, S D=1.20)$. Amotivation was relatively low $(M=2.36$, $S D=1.29)$. See Table A4 in Appendix A for a full overview of the descriptives and correlation coefficients.

Randomization check. We performed the same analyses as in Study 1 and 2 to check for randomization of participants across the two conditions, and included age, gender, goal 
strivings, autonomous motivation, controlled motivation, and amotivation as dependent variables. Results showed that randomization was successful (all ps > .079).

Main analyses. We ran a Chi-squared analysis to analyze the effect of the default nudge on the likelihood of participating in the longer version. The default nudge had a small but significant effect, $\chi^{2}(1)=5.04, p=.025, O R=1.48$, such that more participants chose the longer version in the default condition (46.9\%) than in the control condition (37.4\%).

In order to analyze whether motivation moderates nudge effectiveness, we conducted separate hierarchical logistic regressions on the likelihood of participating in the longer version, starting with the default nudge in step 1 (with the control condition coded as 0 and the default condition coded as 1 ), the motivation measures in step 2 , and the interaction effect in step 3. Not surprisingly, the default nudge turned out significant in our regression models as well $\left(\beta=0.20, p=.025, R_{N}^{2}=0.01\right)$. Model fit did not improve by adding main effects for goal strivings $(p=.412)$, autonomous motivation $(p=.161)$, controlled motivation ( $p=.502)$, or amotivation $(p=602)$, nor did it improve by adding interaction effects (all $p s>.280$ ), and no main effects of or interaction effects with motivation for helping other people were found.

Motivation sustainability. Since the second part of Study 3 was framed as a study on sustainability, we were also interested in the role of motivation to make sustainable choices in relation to the effectiveness of the nudge. We analyzed this by conducting the same hierarchical logistic regressions as for motivation for helping other people, but then with goal strivings, autonomous motivation, controlled motivation, and amotivation for making sustainable choices (See Table 3 for the complete regression results). Adding goal strivings to the base model improved model fit $\left(R_{N}^{2}=0.03, p=.003\right)$, and goal strivings for making sustainable choices significantly predicted the likelihood of participating in the longer 
version $(\beta=.27 p=.003)$. Similarly, adding autonomous motivation to the base model improved model fit $\left(R_{N}^{2}=0.03, p=.017\right)$, and autonomous motivation for making sustainable choices significantly predicted the likelihood of participating in the longer version $(\beta=.21, p=.018)$. Adding controlled motivation to the base model did not improve model fit $(p=.491)$. Adding amotivation for making sustainable choices to the base model marginally significantly improved model fit $\left(R_{N}^{2}=0.02, p=.060\right)$, and amotivation for making sustainable choices marginally significantly predicted the likelihood of participating in the longer version ( $\beta=-.17, p=.062$ ). Adding interaction terms did not improve model fit for any of the motivational constructs (all $p s>.185$ ).

Table 3. Logistic regression model for motivation to make sustainable choices, and with the likelihood of participating in the longer version as dependent variable (Study 3).

\begin{tabular}{|c|c|c|c|c|c|c|c|}
\hline & $\Delta R_{N}^{2}$ & $b(S E)$ & $\beta$ & $O R$ & $95 \% \mathrm{Cl} O R$ & $z$ & $p$ \\
\hline Step 1 & 0.01 & & & & & & .025 \\
\hline Constant & & $-0.52(0.13)$ & & 0.60 & {$[0.47,0.76]$} & -4.13 & $<.001$ \\
\hline Default & & $0.39(0.17)$ & 0.20 & 1.48 & {$[1.05,2.08]$} & 2.24 & .025 \\
\hline Step 2 - Goal strivings & 0.02 & & & & & & .003 \\
\hline Constant & & $-1.47(0.35)$ & & 0.23 & {$[0.11,0.45]$} & -4.20 & $<.001$ \\
\hline Default & & $0.39(0.18)$ & 0.19 & 1.48 & {$[1.05,2.10]$} & 2.23 & .025 \\
\hline Goal strivings & & $0.20(0.07)$ & 0.27 & 1.23 & {$[1.07,1.41]$} & 2.96 & .003 \\
\hline $\begin{array}{l}\text { Step } 2 \text { - Autonomous } \\
\text { motivation }\end{array}$ & 0.01 & & & & & & .017 \\
\hline Constant & & $-1.37(0.39)$ & & 0.25 & {$[0.12,0.54]$} & -3.55 & $<.001$ \\
\hline Default & & $0.39(0.18)$ & 0.20 & 1.48 & {$[1.05,2.09]$} & 2.24 & .025 \\
\hline $\begin{array}{l}\text { Autonomous } \\
\text { motivation }\end{array}$ & & $0.16(0.07)$ & 0.21 & 1.17 & {$[1.03,1.34]$} & 2.36 & .018 \\
\hline $\begin{array}{l}\text { Step } 2 \text { - Controlled } \\
\text { motivation }\end{array}$ & 0.00 & & & & & & .491 \\
\hline
\end{tabular}


$\begin{array}{lll}\text { Step 2-Amotivation } & 0.01 & .060\end{array}$

$\begin{array}{lrrrrrr}\text { Constant } & -0.22(0.20) & & 0.81 & {[0.54,1.20]} & -1.06 & .288 \\ \text { Default } & 0.39(0.18) & 0.20 & 1.48 & {[1.05,2.09]} & 2.24 & .025 \\ \text { Amotivation } & -0.13(0.07) & -0.17 & 0.88 & {[0.77,1.01]} & -1.86 & .062\end{array}$

Note. $\beta$ s are X-standardized. $N=544$.

In order to analyze whether the default adds an increased propensity of choosing the desired option, we also ran stepwise regressions starting with motivation for making sustainable choices in step 1 and adding the condition variable in step 2 . These analyses consistently revealed that the default predicted the likelihood of participating in the longer version when accounting for motivation with small but significant improvements in model fit of $R_{N}^{2}=0.01$ (See Online Supplementary Materials for full details).

\section{Discussion Study 3}

In Study 3 we again found a significant default effect and showed that the default manipulation increased participation in the longer questionnaire. We intended to replicate findings from Study 1 and 2 with another default nudge that we anticipated to qualify as a different kind of behavior than the behaviors studied in Study 1 and 2. We expected to find effects of goal strivings and autonomous motivation to help other people on our behavior of interest (participating in a longer version). Yet, it seems that this behavior was not seen as an act of helping other people, as our motivational measures of helping other people did not have any predictive value. This was also affirmed by anecdotal evidence from the openended question at the end of the study, in which participants could enter any final thoughts after the debriefing. In this open-ended question, some participants indicated that they would only regard participating in a longer questionnaire as helping other people if they 
knew whom they would be helping, which was not the case in our study. This complicated the goal of answering our main research question on the role of motivation.

However, we informed participants that the second study would be about sustainability and had included measures of motivation for making sustainable choices in the first study. Exploratory analyses revealed that the motivation to make sustainable choices did affect the decision to participate in a longer version of our questionnaire on sustainability, and thus it is likely that participants attributed this decision as an act of sustainability. When looking at the role of motivation to make sustainable choices in nudging participation in a longer version on sustainability, a similar pattern of results emerged as in studies 1 and 2 . Autonomous motivation and goal strivings had positive main effects on the decision, amotivation had a (marginally significant) negative main effect on the decision, but controlled motivation did not affect the decision. We also did not find any significant interaction effects.

\section{General Discussion}

In three high-powered studies we investigated the role of motivation for the effectiveness of nudging interventions. How nudges and motivation together predict behavior was thus far not clear, nor whether relatively small interventions like nudges can in fact add an increased propensity to perform desirable behavior when accounting for people's motivation. To address this, we conducted three studies with different types of defaults across different behavioral domains, and we focused on a generic measure of motivation strength (goal strivings) as well as on autonomous motivation, controlled motivation, and amotivation.

Across three studies we consistently found significant default effects. The effect sizes varied greatly and were thus heterogenous across the three studies, ranging from small 
(Study 3) to very large (Study 2). This is consistent with a recent meta-analysis which revealed an average medium to large effect size of defaults, but with considerable heterogeneity across studies (Jachimowicz et al., 2019). In our studies, the size of the default effect was likely to be contingent on the operationalization of the default as well as the impact of the choice on behavior. For example, in Study 2 - the study with the largest effect size - we implemented an all-or-nothing default such that all 14 amenities were either preselected or not. In contrast, in Study 3 - the study with the smallest effect size - only one option was preselected and the nudged choice had immediate behavioral implications. Nevertheless, in line with previous studies we found robust evidence in the current set of studies that defaults can effectively steer behavior across a range of different behaviors with practically meaningful effect sizes.

We also found consistent evidence over different behavioral domains that goal strivings and autonomous motivation significantly predict behavior in the presence of a default. That is, across the behavioral domains of healthy eating and sustainability, and thus across pro-self and pro-social nudges, we found that goal strivings and autonomous motivation had a significant main effect on the behavior of interest. This corroborates findings from studies on the role attitudes in nudges' effectiveness (Kaiser et al., 2020; Kuhn et al., 2020; Taube \& Vetter, 2019; Vetter \& Kutzner, 2016), which have also revealed main effects only on behavioral outcomes. Controlled motivation did not affect our behavioral outcomes in Study 1 and 3, while it significantly predicted sustainable behavior in Study 2, but with negligible predictive power and little practical significance. We thus showed that autonomous motivation is a consistent driver of healthy and sustainable behavior, while controlled motivation is not. This is largely in line with previous studies based on SelfDetermination Theory which have shown larger and more consistent effects of more self- 
determined motivations across a range of healthy and sustainable behaviors (e.g., Hagger et al., 2014; Pelletier, 2002). Finally, amotivation negatively affected our behavioral outcomes, but we only analyzed amotivation exploratory and with low internal reliability. We do note that in Study 3 we did not find any effects of motivation to help other people, but in retrospect we believe that participants did not consider the behavior of interest as an act of helping other people but rather as an act of sustainability since the cover story instructed them that the study would be about this topic.

Across the three studies, we did not observe any significant interaction patterns between the default nudge and motivation. We did not test for equivalence or weigh the strength of evidence for this null-effect, but we can conclude that we have not found evidence that the default effect was moderated by a certain level or type of motivation in our sample. The absence of these interaction effects could imply that motivation does not constitute a boundary condition for nudge effectiveness. Yet, we believe that this conclusion is premature, given that people were already moderately to strongly motivated to perform the behavior that was stimulated. As most nudges are intended to stimulate rather undisputed and simplified behaviors, we are not the first to encounter this practical limitation (e.g., Venema et al., 2019). Nevertheless, given these high scores on motivation, it was particularly relevant to observe that the default nudges still stimulated behavior when accounting for this strong motivation, suggesting that defaults do indeed have added value for motivated behavior. If motivation were to form a boundary condition such that people who are not motivated will not be nudged, one would require a more controversial behavior or a more diverse sample with more variation in the types and strength of motivation. In a way, this could eventually become more of a theoretical exercise than a practically informative discussion, as nudges are by and large intended to stimulate behaviors that are 
either beneficial for individuals themselves or society at large, but it nevertheless remains an important void in nudging research to fill.

\section{Implications}

In line with previous studies, we show that defaults can have a considerable impact on choice outcomes, but that people are still capable of deviating from the status quo (e.g., Van Gestel et al., 2020a). In a way one could compare this to the anchoring and adjustment heuristic (Tversky \& Kahneman, 1974). The default sets an anchor, from which people can adjust according to the strength and type of motivation. Those who are strongly autonomously motivated are still capable of making more healthy or sustainable choices, while those who are less motivated, or amotivated, are capable of making less healthy or sustainable choices. Relative to each other, results showed that motivation was a stronger predictor in Study 1 and 3, but that the default had a higher impact on sustainable decisions in Study 2.

These findings have practical implications for policy makers who wish to steer behavior according to the libertarian paternalism principle (Thaler \& Sunstein, 2003). Our results show that defaults are indeed paternalistic in the sense that policy makers have to make a normative decision about what option to make the default, but also that they are libertarian in the sense that individuals can adjust from this anchor according to their own motivation. Yet, policy makers do have to be aware of the absolute strength of the default manipulation, which can differ across types of defaults, as well as its relative strength in relation to motivation, as our studies point out that in some cases the environment may have a larger effect on behavioral outcomes than intra-individual tendencies.

Similarly, this finding has implications for the debate on the ethics of nudges, which is extensively held based on theoretical assumptions. It is often assumed that nudges may 
violate autonomy through manipulation (Hansen \& Jespersen, 2013; Wilkinson, 2013), and need for autonomy may be decreased if defaults are installed for choices that would be fairly simple to make without the nudge (Arvantitis et al., 2020). Yet, for more complex choices this hampering effect on autonomy does not seem to exist, and recent insights have also inspired the perspective that nudges may support people live their lives without the necessity of continuous deliberation to act upon their intentions (De Ridder et al., 2020; Vugts et al., 2020). The current studies offer empirical data to inform this debate and demonstrate that default nudges are effective in stimulating behavior that people are generally motivated for. According to Bovens (2009), nudges that bring people's actions in line with their own preferences, or nudges that are in people' own interest, are more legitimate. In our studies we could argue that this was the case. Across all three studies, the default effects did not cancel out any motivational effects, but instead gave people an additional push in performing the behavior that they were motivated for. In fact, in our studies, in which people were overall highly motivated to perform the desirable behavior, one could argue that the default leverages individual's motivation, a phenomenon referred to as facilitation (Saghai, 2013). Yet, the more crucial question for the legitimacy of nudging is whether actions would remain in line with people's own intentions if those are opposite of the intention of the nudge. The implications of the current studies for the ethics of nudging are thus limited to the higher spectrum of motivational strength, while concerns are more pronounced for the lower spectrum.

\section{Limitations and future research}

There are several limitations to our studies that should be taken into account when interpreting these findings. First and foremost, our studies are limited to behaviors that people, at least on a group level, are moderately to highly motivated for. On average, 
motivation for healthy eating and making sustainable choices was relatively high in our samples, and these behaviors are the two most frequently nudged behaviors in empirical research (Szaszi et al., 2017). One could argue that these kinds of behaviors that people are motivated for are ideally suitable for nudging and that this makes it more legitimate, but the legitimate use of nudges in empirical research could eventually hinder gaining further insights in possible boundary conditions. The implications of these studies are mostly applicable to the idea of nudging for the common good, while it may not shed as much light on those individuals who are clearly opposed to this given behavior. The linear trends that we found in our studies should thus be interpreted with caution, and future research should investigate whether these trends uphold for behaviors with more variation in motivational strength across people. Especially, further research is needed to study the role of motivation in nudging people with low motivation (i.e., counteractive motives) and (stronger) amotivation (i.e., indifference), as in our studies we were only able to include amotivation exploratorily with poor to questionable internal reliability. We expect that the reduction of meat consumption could be an interesting behavior of interest for future research on boundary conditions, as the motivation to perform this behavior is less widespread across the population with a substantial group of fully committed meat eaters (Malek et al., 2019). Furthermore, another approach where defaults are installed that promote unhealthy or unsustainable options could aid in painting a completer picture of the relationship between motivation and nudge effectiveness.

Another limitation of our studies is that we only used default nudges, which are oftentimes referred to as the most prototypical type 1 nudge (i.e., requiring the least cognitive effort to be effective; Hansen \& Jespersen, 2013; Jung \& Mellers, 2016; Sunstein, 2016). A remaining question is whether our results, which are robust across different types 
of defaults, are also robust across different types of nudges, such as social proof (Venema et al., 2020) or environmental restructuring (Van Gestel et al., 2018; Van Gestel et al., 2020b). Finally, it should be noted that we only measured motivation, and that manipulations of motivation could further strengthen the evidence base.

\section{Conclusion}

In conclusion, we showed that a default nudge and motivation both have a main effect on behaviors that people are at least moderately motivated for. The default nudge sets the anchor, from which people can adjust according to the type and strength of their motivation. This implies that autonomous decision making is still possible, even if the environmental manipulation may have a considerable effect on behavior. If nudges are indeed implemented as they are intended (i.e., "Nudge for good"), they will likely support people to act in line with their own motivation. However, our results are limited to those cases in which the goal of the nudge is in line with the motivational orientation of the individual and future research is still required in order to study whether nudges leave room for an emergency exit in case the direction of the nudge is against people's own wishes. 


\section{References}

Anwyl-Irvine, A. L., Massonnié, J., Flitton, A., Kirkham, N., \& Evershed, J. K. (2020). Gorilla in our midst: An online behavioral experiment builder. Behavior Research Methods, 52(1), 388-407. doi: 10.3758/s13428-019-01237-x

Arvanitis, A., Kalliris, K., \& Kaminiotis, K. (2019). Are defaults supportive of autonomy? An examination of nudges under the lens of Self-Determination Theory. The Social Science Journal. doi: 10.1016/j.soscij.2019.08.003

Antonides, G., \& Welvaarts, M. (2020). Effects of default option and lateral presentation on consumer choice of the sustainable option in an online choice task. Sustainability, 12(13), 5484. doi: 10.3390/su12135484

Baumeister, R. F., Bratslavsky, E., Muraven, M., \& Tice, D. M. (1998). Ego depletion: Is the active self a limited resource? Journal of Personality and Social Psychology, 74(5), 1252-1265. doi: 10.1037/0022-3514.74.5.1252

Beauchamp, A., Backholer, K., Magliano, D., \& Peeters, A. (2014). The effect of obesity prevention interventions according to socioeconomic position: A systematic review. Obesity Reviews, 15(7), 541-554. doi: 10.1111/obr.12161

Benartzi, S., Beshears, J., Milkman, K. L., Sunstein, C. R., Thaler, R. H., Shankar, M., TuckerRay, W., Congdon, W. J., \& Galing, S. (2017). Should governments invest more in nudging? Psychological Science, 28(8), 1041-1055. doi: 10.1177/0956797617702501

Bovens, L. (2009). The ethics of nudge. In T. Grüne-Yanoff \& S. O. Hansson (Eds.), Preference Change: Approaches from Philosophy, Economics and Psychology, (pp. 207-219). New York: Springer. 
Coffino, J. A., Udo, T., \& Hormes, J. M. (2020). Nudging while online grocery shopping: A randomized feasibility trial to enhance nutrition in individuals with food insecurity. Appetite, 152, 104714. doi: j.appet.2020.104714

Deci, E. L., \& Ryan, R. M. (2000). The "what" and "why" of goal pursuits: Human needs and the self-determination of behavior. Psychological Inquiry, 11(4), 227-268. doi: 10.1207/s15327965pli1104_01

Emmons, R. A. (1986). Personal strivings: An approach to personality and subjective wellbeing. Journal of Personality and Social Psychology, 51, 1058-1068. doi: $10.1037 / 0022-3514.51 .5 .1058$

Van Gestel, L. C., Adriaanse, M. A., \& De Ridder, D. T. D. (2020a). Do nudges make use of automatic processing? Unraveling the effects of a default nudge under type 1 and type 2 processing. Comprehensive Results in Social Psychology. doi: $10.1080 / 23743603.2020 .1808456$

Van Gestel, L. C., Adriaanse, M. A., \& De Ridder, D. T. D. (2020b). Beyond discrete choices Investigating the effectiveness of a proximity nudge with multiple alternative options. Frontiers in Psychology, 11. doi: 10.3389/fpsyg.2020.01211

Van Gestel, L. C., Adriaanse, M. A., \& De Ridder, D. T. D. (2021). The role of motivation in nudging. Retrieved from osf.io/sbq87

Van Gestel, L. C., Kroese, F. M., \& De Ridder, D. T. D. (2018). Nudging at the checkout counter - A longitudinal study of the effect of a food repositioning nudge on healthy food choice. Psychology \& Health, 33, 800-809. doi:

$10.1080 / 08870446.2017 .1416116$

Hagger, M. S., Hardcastle, S. J., Chater, A., Mallett, C., Pal, S., \& Chatzisarantis, N. L. D. (2014). Autonomous and controlled motivational regulations for multiple health- 
related behaviors: between-and within-participants analyses. Health Psychology and Behavioral Medicine: An Open Access Journal, 2(1), 565-601. doi:

$10.1080 / 21642850.2014 .912945$

Hansen, P. G., \& Jespersen, A. M. (2013). Nudge and the manipulation of choice. A framework for the responsible use of the nudge approach to behaviour change in public policy. European Journal of Risk Regulation, 4(1), 3-28. doi:

$10.1017 / \mathrm{S} 1867299 \times 00002762$

Hunter, J. A., Hollands, G. J., Couturier, D.-L., \& Marteau, T. M. (2018). Effect of snack-food proximity on intake in general population samples with higher and lower cognitive resource. Appetite, 121, 337-347. doi: 10.1016/j.appet.2017.11.101

Jachimowicz, J. M., Duncan, S., Weber, E. U., \& Johnson, E. J. (2019). When and why defaults influence decisions: A meta-analysis of default effects. Behavioral Public Policy, 3(2), 159-186. doi: 10.1017/bpp.2018.43

Johnson, E. J., \& Goldstein, D. (2003). Do defaults save lives? Science, 302(5649), 1338-1339. doi: $10.1126 /$ science.1091721

Jung, J. Y., \& Mellers, B. A. (2016). American attitudes toward nudges. Judgment \& Decision Making, 11(1).

Kaiser, M., Bernauer, M., Sunstein, C. R., \& Reisch, L. A. (2020). The power of green defaults: the impact of regional variation of opt-out tariffs on green energy demand in Germany. Ecological Economics, 174, 106685. doi: 10.1016/j.ecolecon.2020.106685 Kuhn, S., Ihmels, M., \& Kutzner, F. (2020). Organic defaults in online-shopping: Immediate effects but no spillover to similar choices. Journal of Consumer Behaviour, 1-15. doi: $10.1002 / c b .1850$ 
Levesque, C. S., Williams, G. C., Elliot, D., Pickering, M. A., Bodenhamer, B., \& Finley, P. J. (2007). Validating the theoretical structure of the Treatment Self-Regulation Questionnaire (TSRQ) across three different health behaviors. Health Education Research, 22(5), 691-702. doi: 10.1093/her/cyl148

Lorenc, T., Petticrew, M., Welch, V., \& Tugwell, P. (2013). What types of interventions generate inequalities? Evidence from systematic reviews. Journal of Epidemiology and Community Health, 67(2), 190-193. doi: 10.1136/jech-2012-201257

Madrian, B. C. , \& Shea, D. F. (2001). The power of suggestion: Inertia in 401 (k) participation and savings behavior. The Quarterly Journal of Economics, 116(4), 1149-1187. doi: $10.1162 / 003355301753265543$

Malek, L., Umberger, W. J., \& Goddard, E. (2019). Committed vs. uncommitted meat eaters: Understanding willingness to change protein consumption. Appetite, 138, 115-126. doi: 10.1016/j.appet.2019.03.024

McGill, R., Anwar, E., Orton, L., Bromley, H., Lloyd-Williams, F., O’Flaherty, M., TaylorRobinson, R., Guzman-Castillo, M., Gillespie, D., Moreira, P., Allen, K., Hyseni, L., Calder, N., Petticrew, M., White, M., Whitehead, M., \& Capewell, S. (2015). Are interventions to promote healthy eating equally effective for all? Systematic review of socioeconomic inequalities in impact. BMC Public Health, 15, 457. doi:

$10.1186 / \mathrm{s} 12889-015-1781-7$

Pelletier, L. G. (2002). A Motivational Analysis of Self-Determination for Pro-Environmental Behaviors. In E. L. Deci \& R. M. Ryan (Eds.), Handbook of Self-Determination Research (pp. 205-232). Rochester, NY: University of Rochester Press. 
Pichert, D., \& Katsikopoulos, K. V. (2008). Green defaults: Information presentation and proenvironmental behaviour. Journal of Environmental Psychology, 28(1), 63-73. doi: 10.1016/j.jenvp.2007.09.004

De Ridder, D. T. D., Feitsma, J., Van den Hoven, M., Kroese, F., Schillemans, T., Verweij, M., Venema, T., Vugts, A., \& De Vet, E. (2020). Simple nudges that are not so easy. Behavioural Public Policy. doi: 10.1017/bpp.2020.36

De Ridder, D. T. D., Kroese, F. M., \& Van Gestel, L. C. (in press). Nudgeability: Mapping conditions of susceptibility to nudge influence. Perspectives on Psychological Science.

Ryan, R. M., \& Deci, E. L. (2000). Self-determination theory and the facilitation of intrinsic motivation, social development, and well-being. American Psychologist, 55(1), 68-78. doi: $10.1037 / 0003-066 x \cdot 55.1 .68$

Saghai, Y. (2013). Salvaging the concept of nudge. Journal of Medical Ethics, 39(8), 487-493. doi: 10.1136/medethics-2012-100727

Sheeran, P., \& Webb, T. L. (2016). The intention-behavior gap. Social and Personality Psychology Compass, 10(9), 503-518. doi: 10.1111/spc3.12265

Steffel, M., Williams, E. F., \& Pogacar, R. (2016). Ethically deployed defaults: Transparency and consumer protection through disclosure and preference articulation. Journal of Marketing Research, 53(5), 865-880. doi: 10.1509/jmr.14.0421

Sunstein, C. R. (2016). The Ethics of Influence: Government in the Age of Behavioral Science. Cambridge, United Kingdom: Cambridge University Press.

Sunstein, C. R., \& Thaler, R. H. (2003). Libertarian paternalism is not an oxymoron. The University of Chicago Law Review, 70(4), 1159-1202. doi: 10.2307/1600573

Swinburn, B., Egger, G., \& Raza, F. (1999). Dissecting obesogenic environments: the development and application of a framework for identifying and prioritizing 
environmental interventions for obesity. Preventive Medicine, 29, 563-570. doi: 10.1006/pmed.1999.0585

Szaszi, B., Palinkas, A., Palfi, B., Szollosi, A., \& Aczel, B. (2017). A systematic scoping review of the choice architecture movement: Toward understanding when and why nudges work. Journal of Behavioral Decision Making, 31(3), 355-366. doi: 10.1002/bdm.2035

Taube, O., \& Vetter, M. (2019). How green defaults promote environmentally friendly decisions: Attitude-conditional default acceptance but attitude-unconditional effects on actual choices. Journal of Applied Social Psychology, 49, 721-732. doi:

10.1111/jasp.12629

Thaler, R. H., \& Sunstein, C. R. (2003). Libertarian paternalism. American economic review, 93(2), 175-179. doi: 10.1257/000282803321947001

Thaler R. H., \& Sunstein, C. R. (2008). Nudge: Improving Decisions About Health, Wealth, and Happiness. New Haven, CT: Yale University Press.

Tversky, A., \& Kahneman, D. (1974). Judgment under uncertainty: Heuristics and biases. Science, 185(4157), 1124-1131. doi: 10.1126/science.185.4157.1124

Venema, T. A., Kroese, F. M., Benjamins, J. S., \& de Ridder, D. T. (2020). When in Doubt, Follow the Crowd? Responsiveness to Social Proof Nudges in the Absence of Clear Preferences. Frontiers in Psychology, 11, 1385. doi: 10.3389/fpsyg.2020.01385

Venema, T. A., Kroese, F. M., De Vet, E., \& De Ridder, D. T. (2019). The One that I Want: Strong personal preferences render the center-stage nudge redundant. Food Quality and Preference, 78, 103744. doi: 10.1016/j.foodqual.2019.103744

Vetter, M., \& Kutzner, F. (2016). Nudge me if you can - how defaults and attitude strength interact to change behavior. Comprehensive Results in Social Psychology, 1(1-3), 8-34. doi: $10.1080 / 23743603.2016 .1139390$ 
Vugts, A., Van Den Hoven, M., De Vet, E., \& Verweij, M. (2020). How autonomy is understood in discussions on the ethics of nudging. Behavioural Public Policy, 4(1), 108-123. doi: 10.1017/bpp.2018.5

Wachner, J., Adriaanse, M., \& De Ridder, D. (2020). The influence of nudge transparency on the experience of autonomy. Comprehensive Results in Social Psychology. doi: $10.1080 / 23743603.2020 .1808782$

Wilkinson, T. M. (2013). Nudging and manipulation. Political Studies, 61(2), 341-355. doi: 10.1111/j.1467-9248.2012.00974.x

Wilkowski, B. M., Ferguson, E. L., Williamson, L. Z., \& Lappi, S. K. (2018). (How) does initial self-control undermine later self-control in daily life? Personality and Social Psychology Bulletin, 44(9), 1315-1329. doi: 10.31234/osf.io/zh74y 


\section{Appendix A}

Table A1. Descriptives and correlation coefficients for autonomous motivation, controlled motivation, and goal strivings for eating healthily (Study 1).

\begin{tabular}{lllllll}
\hline & Mean (SD) & Range & 1 & 2 & 3 & 4 \\
\hline 1. Goal strivings & $4.95(1.14)$ & $1-7$ & $(.77)$ & & & \\
2. Autonomous motivation & $5.53(1.02)$ & $1-6.50$ & $.73^{* * *}$ & $(.86)$ & & \\
3. Controlled motivation & $3.31(1.23)$ & $1-7$ & $.30^{* * *}$ & $.21^{* * *}$ & $(.82)$ & \\
4. Amotivation & $2.47(1.11)$ & $1-6$ & $-.46^{* * *}$ & $-.50^{* * *}$ & .02 & $(.56)$
\end{tabular}

Note. Cronbach's alphas are shown in the diagonal. $N=635$.

$* * * p<.001$

Table A2. Descriptives and correlation coefficients for autonomous motivation, controlled motivation, and goal strivings for making sustainable choices (Study 2).

\begin{tabular}{lllllll}
\hline & Mean (SD) & Range & 1 & 2 & 3 & 4 \\
\hline 1. Goal strivings & $4.65(1.22)$ & $1-7$ & $(.87)$ & & & \\
2. Autonomous motivation & $4.87(1.34)$ & $1-7$ & $.78^{* * *}$ & $(.93)$ & & \\
3. Controlled motivation & $3.33(1.14)$ & $1-7$ & $.33^{* * *}$ & $.36^{* * *}$ & $(.81)$ & \\
4. Amotivation & $2.70(1.26)$ & $1-7$ & $-.47^{* * *}$ & $-.55^{* * *}$ & $-.17^{* * *}$ & $(.67)$
\end{tabular}

Note. Cronbach's alphas are shown in the diagonal. $N=534$.

$* * * p<.001$

Table A3. Descriptives and correlation coefficients for autonomous motivation, controlled motivation, and goal strivings for helping other people (Study 3).

\begin{tabular}{lllllll}
\hline & Mean (SD) & Range & 1 & 2 & 3 & 4 \\
\hline 1. Goal strivings & $5.37(1.07)$ & $1.25-7$ & $(.81)$ & & & \\
2. Autonomous motivation & $5.26(1.08)$ & $1.50-7$ & $.67^{* * *}$ & $(.84)$ & & \\
3. Controlled motivation & $3.78(1.18)$ & $1-7$ & $.29^{* * *}$ & $.30^{* * *}$ & $(.80)$ & \\
4. Amotivation & $2.33(1.09)$ & $1-6.67$ & $-.25^{* * *}$ & $-.28^{* * *}$ & $.22^{* * *}$ & $(.58)$ \\
\hline
\end{tabular}

Note. Cronbach's alphas are shown in the diagonal. $N=544$.

$* * * p<.001$ 
Table A4. Descriptives and correlation coefficients for autonomous motivation, controlled motivation, and goal strivings for making sustainable choices (Study 3).

\begin{tabular}{lllllll}
\hline & Mean (SD) & Range & 1 & 2 & 3 & 4 \\
\hline 1. Goal strivings & $4.66(1.31)$ & $1-7$ & $(.79)$ & & & \\
2. Autonomous motivation & $5.30(1.33)$ & $1-7$ & $.79 * * *$ & $(.93)$ & & \\
3. Controlled motivation & $3.61(1.20)$ & $1-6.67$ & $.37^{* * *}$ & $.44^{* * *}$ & (.79) & \\
4. Amotivation & $2.36(1.29)$ & $1-6$ & $-.48^{* * *}$ & $-.56^{* * *}$ & $.10^{*}$ & $(.68)$
\end{tabular}

Note. Cronbach's alphas are shown in the diagonal. $N=544$.

$* * * p<.001, * p<.05$ 


\section{ONLINE SUPPLEMENTAL MATERIAL}

\section{Study 2}

For exploratory purposes, we analyzed whether there was a difference between the two conditions in satisfaction with the chosen amenities. The independent samples t-test revealed that participants in the default condition $(M=6.14, S D=.93)$ were more satisfied than participants in the control condition $(M=5.68, S D=.94), t(532)=-5.75, p<.001, d=$ .50. Satisfaction correlated positively with autonomous motivation $(r=.19, p<.001)$ and goal strivings $(r=.19, p<.001)$, and correlated negatively with amotivation $(r=-.11, p=$ .009), but not with controlled motivation $(p=.097)$.

\section{Study 3}

For exploratory purposes, we again analyzed whether there was a difference between the two conditions in choice satisfaction. The independent samples t-test revealed no difference between the two conditions $(p=.455)$. Satisfaction correlated negatively with controlled motivation ( $r=-.13, p=.002)$, but not with goal strivings $(p=.107)$, autonomous motivation $(p=.116)$ and amotivation $(p=.230)$. We further explored for differences in acceptability and intrusiveness. The independent samples t-test revealed no difference between the two conditions in acceptability $(p=.132)$ and revealed a marginally significant effect of the default on intrusiveness $(p=.053)$, with higher scores in the default condition $(M=3.38, S D=2.14)$ than in the control condition $(M=3.01, S D=2.25)$. Acceptability correlated positively with goal strivings $(r=.09, p=.035)$ and autonomous motivation $(r=$ $.11, p=.010)$, and negatively with amotivation $(r=-.09, p=.043)$, but not with controlled motivation $(p=.188)$. Intrusiveness did not correlate with goal strivings $(p=.373)$, autonomous motivation $(p=.526)$, controlled motivation $(p=.635)$, or amotivation $(p=$ $.085)$. 


\section{STEPWISE REGRESSIONS STARTING WITH MOTIVATION STUDY 1}

Table 1. Regression model with the proportion of nudged healthy food choices as dependent variable, and goal strivings (Step 1), default (Step 2), and interaction effect (Step 3) as independent variables (Study 1).

\begin{tabular}{lrrrrrr}
\hline & $\Delta R_{a d j}{ }^{2}$ & $b(S E)$ & $\beta$ & $95 \% C l b$ & $t$ & $p$ \\
\hline Step 1-Goal strivings & 0.06 & & & & & $<.001$ \\
$\quad$ Constant & & $0.08(0.03)$ & & {$[0.02,0.15]$} & 2.52 & .012 \\
Goal strivings & & $0.04(0.01)$ & 0.25 & {$[0.03,0.06]$} & 6.52 & $<.001$ \\
Step 2-Goal strivings & 0.03 & & & & & $<.001$ \\
Constant & & $0.05(0.03)$ & & {$[-0.02,0.12]$} & 1.50 & .133 \\
Goal strivings & & $0.04(0.01)$ & 0.25 & {$[0.03,0.06]$} & 6.63 & $<.001$ \\
Default & & $0.07(0.01)$ & 0.17 & {$[0.04,0.10]$} & 4.49 & $<.001$ \\
Step 3 - Goal Strivings & 0.00 & & & & .545 \\
Constant & & $0.07(0.05)$ & & {$[-0.02,0.16]$} & 1.50 & .135 \\
Goal strivings & & $0.04(0.01)$ & 0.25 & {$[0.02,0.06]$} & 4.16 & $<.001$ \\
Default & & $0.03(0.07)$ & 0.17 & {$[-0.10,0.16]$} & 0.41 & .681 \\
Goal strivings X Default & & $0.01(0.01)$ & 0.02 & {$[-0.02,0.03]$} & 0.60 & .545 \\
\hline
\end{tabular}

Note. $\beta$ s are fully standardized. $N=635$.

Table 2. Regression model with the proportion of nudged healthy food choices as dependent variable, and autonomous motivation (Step 1), default (Step 2), and interaction effect (Step 3) as independent variables (Study 1).

\begin{tabular}{lrrrrrr}
\hline & $\Delta R_{a d j}{ }^{2}$ & $b(S E)$ & $\beta$ & $95 \% \mathrm{Cl} b$ & $t$ & $p$ \\
\hline $\begin{array}{l}\text { Step 1 - Autonomous } \\
\text { motivation }\end{array}$ & 0.06 & & & & & $<.001$ \\
$\quad$ & & & & & & \\
$\quad$ Constant & & $0.04(0.04)$ & & {$[-0.04,0.12]$} & 1.00 & .319 \\
$\quad$ Autonomous motivation & & $0.05(0.01)$ & 0.24 & {$[0.03,0.06]$} & 6.32 & $<.001$ \\
Step 2-Autonomous & 0.02 & & & & & $<.001$ \\
motivation & & & & & & \\
$\quad$ Constant & & $0.02(0.04)$ & & {$[-0.06,0.10]$} & 0.47 & .641 \\
$\quad$ Autonomous motivation & & $0.04(0.01)$ & 0.24 & {$[0.03,0.06]$} & 6.17 & $<.001$
\end{tabular}


Default

$$
0.06(0.01) \quad 0.16
$$

$[0.03,0.09]$

$4.13<.001$

Step 3 - Autonomous

0.00

.876

motivation

$\begin{array}{lrrrrr}\text { Constant } & 0.03(0.06) & & {[-0.08,0.13]} & 0.45 & .654 \\ \text { Autonomous motivation } & 0.04(0.01) & 0.24 & {[0.02,0.06]} & 4.37 & <.001 \\ \text { Default } & 0.05(0.08) & 0.16 & {[-0.11,0.21]} & 0.60 & .552 \\ \text { Autonomous motivation } & 0.00(0.01) & 0.01 & {[-0.03,0.03]} & 0.16 & .876 \\ \text { X Default } & & & & & \end{array}$

Note. $\beta$ s are fully standardized. $N=635$.

Table 3. Regression model with the proportion of nudged healthy food choices as dependent variable, and controlled motivation (Step 1), default (Step 2), and interaction effect (Step 3) as independent variables (Study 1).

\begin{tabular}{|c|c|c|c|c|c|c|}
\hline & $\Delta R_{a d j}^{2}$ & $b(S E)$ & $\beta$ & $95 \% \mathrm{Cl} b$ & $t$ & $p$ \\
\hline $\begin{array}{l}\text { Step } 1 \text { - Controlled } \\
\text { motivation }\end{array}$ & 0.00 & & & & & .291 \\
\hline Constant & & $0.28(0.02)$ & & {$[0.23,0.32]$} & 12.41 & $<.001$ \\
\hline Controlled motivation & & $0.01(0.01)$ & 0.04 & {$[-0.01,0.02]$} & 1.06 & .291 \\
\hline $\begin{array}{l}\text { Step } 2 \text {-Controlled } \\
\text { motivation }\end{array}$ & 0.03 & & & & & $<.001$ \\
\hline Constant & & $0.23(0.02)$ & & {$[0.19,0.28]$} & 10.05 & $<.001$ \\
\hline Controlled motivation & & $0.01(0.01)$ & 0.05 & {$[-0.00,0.02]$} & 1.30 & .193 \\
\hline Default & & $0.07(0.02)$ & 0.17 & {$[0.04,0.10]$} & 4.40 & $<.001$ \\
\hline $\begin{array}{l}\text { Step } 3 \text { - Controlled } \\
\text { motivation }\end{array}$ & 0.00 & & & & & .697 \\
\hline Constant & & $0.25(0.03)$ & & {$[0.18,0.31]$} & 7.73 & $<.001$ \\
\hline Controlled motivation & & $0.01(0.01)$ & 0.05 & {$[-0.01,0.02]$} & 0.64 & .522 \\
\hline Default & & $0.05(0.04)$ & 0.17 & {$[-0.03,0.14]$} & 1.17 & .244 \\
\hline Controlled motivation $\mathrm{X}$ & & $0.00(0.01)$ & 0.02 & {$[-0.02,0.03]$} & 0.39 & .697 \\
\hline Default & & & & & & \\
\hline
\end{tabular}

Note. $\beta$ s are fully standardized. $N=635$. 
Table 4. Regression model with the proportion of nudged healthy food choices as dependent variable, and amotivation (Step 1), default (Step 2), and interaction effect (Step 3) as independent variables (Study 1).

\begin{tabular}{lrrrrrr}
\hline & $\Delta R_{a d j}{ }^{2}$ & $b(S E)$ & $\beta$ & $95 \% \mathrm{Cl} b$ & $t$ & $p$ \\
\hline Step 1-Amotivation & 0.07 & & & & & $<.001$ \\
Constant & & $0.41(0.02)$ & & {$[0.38,0.45]$} & 22.77 & $<.001$ \\
Amotivation & & $-0.05(0.01)$ & -0.27 & {$[-0.06,-0.03]$} & -7.03 & $<.001$ \\
Step 2-Amotivation & 0.03 & & & & & $<.001$ \\
Constant & & $0.38(0.02)$ & & {$[0.34,0.42]$} & 19.97 & $<.001$ \\
Amotivation & & $-0.05(0.01)$ & -0.28 & {$[-0.06,-0.04]$} & -7.32 & $<.001$ \\
Default & & $0.07(0.01)$ & 0.18 & {$[0.04,0.10]$} & 4.78 & $<.001$ \\
Step 3-Amotivation & 0.00 & & & & & .811 \\
Constant & & $0.38(0.03)$ & & {$[0.33,0.43]$} & 14.85 & $<.001$ \\
Amotivation & & $-0.05(0.01)$ & -0.28 & {$[-0.07,-0.03]$} & -4.89 & $<.001$ \\
Default & & $0.08(0.04)$ & 0.18 & {$[0.01,0.15]$} & 2.17 & .030 \\
Amotivation X Default & & $-0.00(0.01)$ & -0.01 & {$[-0.03,0.02]$} & -0.24 & .811 \\
\hline
\end{tabular}

Note. $\beta$ s are fully standardized. $N=635$. 


\section{STEPWISE REGRESSIONS STARTING WITH MOTIVATION STUDY 2}

Table 5. Regression model with the number of green amenities as dependent variable, and goal strivings (Step 1), default (Step 2), and interaction effect (Step 3) as independent variables (Study 2).

\begin{tabular}{lrrrrrr}
\hline & $\Delta R_{a d j}{ }^{2}$ & $b(S E)$ & $\beta$ & $95 \% \mathrm{Cl} b$ & $t$ & $p$ \\
\hline Step 1-Goal strivings & 0.02 & & & & & .002 \\
$\quad$ Constant & & $6.98(0.64)$ & & {$[5.72,8.23]$} & 10.92 & $<.001$ \\
$\quad$ Goal strivings & & $0.42(0.13)$ & 0.13 & {$[0.15,0.68]$} & 3.13 & .002 \\
Step 2-Goal strivings & 0.54 & & & & & $<.001$ \\
Constant & & $3.81(0.45)$ & & {$[2.94,4.69]$} & 8.54 & $<.001$ \\
Goal strivings & & $0.50(0.09)$ & 0.16 & {$[0.32,0.67]$} & 5.57 & $<.001$ \\
Default & & $5.54(0.22)$ & 0.74 & {$[5.11,5.97]$} & 25.46 & $<.001$ \\
Step 3-Goal Strivings & 0.00 & & & & & .996 \\
Constant & & $3.82(0.60)$ & & {$[2.65,4.99]$} & 6.41 & $<.001$ \\
Goal strivings & & $0.50(0.12)$ & 0.16 & {$[3.84,7.23]$} & 4.06 & $<.001$ \\
Default & & $5.53(0.86)$ & 0.74 & {$[0.26,0.74]$} & 6.43 & $<.001$ \\
Goal strivings X Default & & $0.00(0.17)$ & 0.00 & {$[-0.35,0.35]$} & 0.01 & 0.996 \\
\hline
\end{tabular}

Note. $\beta$ s are fully standardized. $N=534$.

Table 6. Regression model with the number of green amenities as dependent variable, and autonomous motivation (Step 1), default (Step 2), and interaction effect (Step 3) as independent variables (Study 2).

\begin{tabular}{|c|c|c|c|c|c|c|}
\hline & $\Delta R_{a d j}{ }^{2}$ & $b(S E)$ & $\beta$ & $95 \% \mathrm{Cl} b$ & $t$ & $p$ \\
\hline Step 1 - Autonomous & 0.05 & & & & & $<.001$ \\
\hline \multicolumn{7}{|l|}{ motivation } \\
\hline Constant & & $5.72(0.60)$ & & {$[4.54,6.90]$} & 9.52 & $<.001$ \\
\hline Autonomous motivation & & $0.65(0.12)$ & 0.23 & {$[0.42,0.89]$} & 5.50 & $<.001$ \\
\hline Step 2 - Autonomous & 0.53 & & & & & $<.001$ \\
\hline \multicolumn{7}{|l|}{ motivation } \\
\hline Constant & & $3.08(0.41)$ & & {$[2.27,3.89]$} & 7.47 & $<.001$ \\
\hline Autonomous motivation & & $0.63(0.08)$ & 0.22 & {$[0.48,0.79]$} & 7.98 & $<.001$ \\
\hline
\end{tabular}


Default

$$
5.48(0.21)
$$

0.73

$[5.06,5.89]$

$25.91<.001$

Step 3 - Autonomous

0.00

.874

motivation

Constant

$3.02(0.55)$

$[1.93,4.11]$

$5.45<.001$

Autonomous motivation

$0.64(0.11)$

0.22

$[0.43,0.86]$

$5.85<.001$

Default

$5.60(0.80)$

0.73

$[4.03,7.17]$

$6.99<.001$

Autonomous motivation

$-0.03(0.16)$

$-0.00$

$[-0.34,0.29] \quad-0.16$

.874

X Default

Note. $\beta$ s are fully standardized. $N=534$.

Table 7. Regression model with the number of green amenities as dependent variable, and controlled motivation (Step 1), default (Step 2), and interaction effect (Step 3) as independent variables (Study 2).

\begin{tabular}{|c|c|c|c|c|c|c|}
\hline & $\Delta R_{a d j}^{2}$ & $b(S E)$ & $\beta$ & $95 \% \mathrm{Cl} b$ & $t$ & $p$ \\
\hline Step 1 - Controlled & 0.00 & & & & & .099 \\
\hline \multicolumn{7}{|l|}{ motivation } \\
\hline Constant & & $8.12(0.50)$ & & {$[7.14,9.11]$} & 16.18 & $<.001$ \\
\hline Controlled motivation & & $0.24(0.14)$ & 0.07 & {$[-0.04,0.52]$} & 1.65 & 0.099 \\
\hline Step 2-Controlled & 0.54 & & & & & $<.001$ \\
\hline \multicolumn{7}{|l|}{ motivation } \\
\hline Constant & & $5.35(0.36)$ & & {$[4.64,6.06]$} & 14.84 & $<.001$ \\
\hline Controlled motivation & & $0.24(0.10)$ & 0.07 & {$[0.05,0.43]$} & 2.46 & .014 \\
\hline Default & & $5.50(0.22)$ & 0.73 & {$[5.06,5.93]$} & 24.71 & $<.001$ \\
\hline Step 3-Controlled & 0.00 & & & & & .389 \\
\hline \multicolumn{7}{|l|}{ motivation } \\
\hline Constant & & $5.66(0.50)$ & & {$[4.66,6.65]$} & 11.21 & $<.001$ \\
\hline Controlled motivation & & $0.15(0.14)$ & 0.07 & {$[-0.13,0.43]$} & 1.03 & .303 \\
\hline Default & & $4.93(0.69)$ & 0.73 & {$[3.58,6.29]$} & 7.17 & $<.001$ \\
\hline Controlled motivation $X$ & & $0.17(0.20)$ & 0.03 & {$[-0.22,0.55]$} & 0.86 & .389 \\
\hline Default & & & & & & \\
\hline
\end{tabular}

Note. $\beta$ s are fully standardized. $N=534$. 
Table 8. Regression model with the number of green amenities as dependent variable, and amotivation (Step 1), default (Step 2), and interaction effect (Step 3) as independent variables (Study 2).

\begin{tabular}{lrrrrrrr}
\hline & $\Delta R_{a d j}{ }^{2}$ & $b(S E)$ & $\beta$ & $95 \% \mathrm{Cl} b$ & $t$ & $p$ \\
\hline Step 1-Amotivation & 0.03 & & & & & $<.001$ \\
Constant & & $10.24(0.38)$ & & {$[9.49,10.99]$} & 26.82 & $<.001$ \\
Amotivation & & $-0.49(0.13)$ & -0.16 & {$[-0.74,-0.24]$} & -3.84 & $<.001$ \\
Step 2-Amotivation & 0.52 & & & & & $<.001$ \\
Constant & & $7.26(0.29)$ & & {$[6.70,7.82]$} & 25.37 & $<.001$ \\
Amotivation & & $-0.40(0.09)$ & -0.13 & {$[-0.57,-0.23]$} & -4.62 & $<.001$ \\
Default & & $5.45(0.22)$ & 0.72 & {$[5.02,5.88]$} & 24.84 & $<.001$ \\
Step 3-Amotivation & 0.00 & & & & & .214 \\
Constant & & $7.55(0.37)$ & & {$[6.83,8.28]$} & 20.42 & $<.001$ \\
Amotivation & & $-0.51(0.12)$ & -0.13 & {$[-0.75,-0.27]$} & -4.18 & $<.001$ \\
Default & & $4.87(0.52)$ & 0.72 & {$[3.85,5.89]$} & 9.36 & $<.001$ \\
Amotivation X Default & & $0.22(0.17)$ & 0.04 & {$[-0.13,0.56]$} & 1.25 & .214 \\
\hline
\end{tabular}

Note. $\beta$ s are fully standardized. $N=534$. 


\section{STEPWISE REGRESSIONS STARTING WITH MOTIVATION STUDY 3 - HELPING OTHER PEOPLE}

Table 9. Logistic regression model with the likelihood of participating in the longer version as dependent variable, and goal strivings for helping other people (Step 1), default (Step 2), and interaction effect (Step 3) as independent variables (Study 3).

\begin{tabular}{|c|c|c|c|c|c|c|c|}
\hline & $\Delta R_{N}^{2}$ & $b(S E)$ & $\beta$ & $O R$ & $95 \% \mathrm{Cl} O \mathrm{R}$ & $z$ & $p$ \\
\hline Step 1 - Goal strivings & 0.00 & & & & & & .365 \\
\hline Constant & & $-0.72(0.45)$ & -0.32 & 0.49 & {$[0.20,1.17]$} & -1.60 & .111 \\
\hline Goal strivings & & $0.07(0.08)$ & 0.08 & 1.08 & {$[0.92,1.27]$} & 0.90 & .367 \\
\hline Step $2-$ Goal strivings & 0.01 & & & & & & .027 \\
\hline Constant & & $-0.88(0.46)$ & & 0.42 & {$[0.17,1.01]$} & -1.91 & .056 \\
\hline Goal strivings & & $0.07(0.08)$ & 0.07 & 1.07 & {$[0.91,1.26]$} & 0.82 & .413 \\
\hline Default & & $0.39(0.17)$ & 0.19 & 1.47 & {$[1.05,2.07]$} & 2.21 & .027 \\
\hline Step 3-Goal Strivings & 0.00 & & & & & & .280 \\
\hline Constant & & $-1.32(0.62)$ & & 0.27 & {$[0.08,0.88]$} & -2.12 & .034 \\
\hline Goal strivings & & $0.15(0.11)$ & 0.06 & 1.16 & {$[0.93,1.46]$} & 1.32 & .187 \\
\hline Default & & $1.35(0.92)$ & 0.20 & 3.87 & {$[0.65,23.73]$} & 1.48 & .139 \\
\hline Goal strivings $X$ & & $-0.18(0.17)$ & -0.10 & 0.84 & {$[0.60,1.16]$} & -1.08 & .281 \\
\hline Default & & & & & & & \\
\hline
\end{tabular}

Note. $\beta$ s are X-standardized. $N=544$.

Table 10. Logistic regression model with the likelihood of participating in the longer version as dependent variable, and autonomous motivation for helping other people (Step 1), default (Step 2), and interaction effect (Step 3) as independent variables (Study 3).

\begin{tabular}{|c|c|c|c|c|c|c|c|}
\hline & $\Delta R_{N}^{2}$ & $b(S E)$ & $\beta$ & OR & $95 \% \mathrm{Cl} O \mathrm{R}$ & $z$ & $p$ \\
\hline $\begin{array}{l}\text { Step } 1 \text { - Autonomous } \\
\text { motivation }\end{array}$ & 0.01 & & & & & & .136 \\
\hline Constant & & $-0.95(0.44)$ & -0.32 & 0.39 & {$[0.16,0.90]$} & -2.18 & .030 \\
\hline Autonomous motivation & & $0.12(0.08)$ & 0.13 & 1.13 & {$[0.96,1.32]$} & 1.48 & .138 \\
\hline $\begin{array}{l}\text { Step } 2 \text { - Autonomous } \\
\text { motivation }\end{array}$ & 0.01 & & & & & & .029 \\
\hline Constant & & $-1.11(0.45)$ & & 0.33 & {$[0.14,0.78]$} & -2.49 & .013 \\
\hline
\end{tabular}




\begin{tabular}{|c|c|c|c|c|c|c|c|}
\hline Autonomous motivation & & $0.11(0.08)$ & 0.12 & 1.12 & {$[0.96,1.32]$} & 1.39 & .163 \\
\hline Default & & $0.38(0.17)$ & 0.19 & 1.47 & {$[1.04,2.07]$} & 2.18 & .029 \\
\hline Step 3 - Autonomous & 0.00 & & & & & & .558 \\
\hline motivation & & & & & & & \\
\hline Constant & & $-0.87(0.61)$ & & 0.42 & {$[0.12,1.37]$} & -1.42 & .155 \\
\hline Autonomous motivation & & $0.07(0.11)$ & 0.12 & 1.07 & {$[0.86,1.34]$} & 0.59 & .557 \\
\hline Default & & $-0.12(0.88)$ & 0.19 & 0.88 & {$[0.16,4.98]$} & -0.14 & .889 \\
\hline Autonomous motivation & & $0.10(0.16)$ & 0.05 & 1.10 & {$[0.80,1.52]$} & 0.59 & .55 \\
\hline
\end{tabular}

Note. $\beta$ s are $\mathrm{X}$-standardized. $N=544$.

Table 11. Logistic regression model with the likelihood of participating in the longer version as dependent variable, and controlled motivation for helping other people (Step 1), default (Step 2), and interaction effect (Step 3) as independent variables (Study 3).

\begin{tabular}{|c|c|c|c|c|c|c|c|}
\hline & $\Delta R_{N}^{2}$ & $b(S E)$ & $\beta$ & $O R$ & $95 \% \mathrm{Cl} O R$ & $z$ & $p$ \\
\hline $\begin{array}{l}\text { Step } 1 \text { - Controlled } \\
\text { motivation }\end{array}$ & 0.00 & & & & & & .620 \\
\hline Constant & & $-0.18(0.29)$ & & 0.83 & {$[0.47,1.48]$} & -0.62 & .535 \\
\hline Controlled motivation & & $-0.04(0.07)$ & & 0.96 & {$[0.83,1.11]$} & -0.50 & .620 \\
\hline $\begin{array}{l}\text { Step } 2 \text { - Controlled } \\
\text { motivation }\end{array}$ & 0.01 & & & & & & .022 \\
\hline Constant & & $-0.33(0.30)$ & & 0.72 & {$[0.40,1.29]$} & -1.11 & .268 \\
\hline Controlled motivation & & $-0.05(0.07)$ & -0.06 & 0.95 & {$[0.82,1.10]$} & -0.67 & .503 \\
\hline Default & & $0.40(0.18)$ & 0.20 & 1.49 & {$[1.06,2.11]$} & 2.28 & .022 \\
\hline $\begin{array}{l}\text { Step } 3 \text { - Controlled } \\
\text { motivation }\end{array}$ & 0.00 & & & & & & .646 \\
\hline Constant & & $-0.21(0.40)$ & & 0.81 & {$[0.37,1.79]$} & -0.52 & .606 \\
\hline Controlled motivation & & $-0.08(0.11)$ & -0.06 & 0.92 & {$[0.75,1.13]$} & -0.80 & .425 \\
\hline Default & & $0.14(0.59)$ & 0.20 & 1.15 & {$[0.36,3.66]$} & 0.24 & .808 \\
\hline Controlled motivation & & $0.07(0.15)$ & 0.04 & 1.07 & {$[0.80,1.44]$} & 0.46 & .646 \\
\hline X Default & & & & & & & \\
\hline
\end{tabular}


Note. $\beta$ s are $\mathrm{X}$-standardized. $N=544$.

Table 12. Logistic regression model with the likelihood of participating in the longer version as dependent variable, and amotivation for helping other people (Step 1), default (Step 2), and interaction effect (Step 3) as independent variables (Study 3).

\begin{tabular}{lrrrrrrr}
\hline & $\Delta R_{N}^{2}$ & $b(S E)$ & $\beta$ & $O R$ & $95 \%$ Cl OR & $z$ & $p$ \\
\hline Step 1-Amotivation & 0.00 & & & & & .698 \\
Constant & & $-0.25(0.20)$ & -0.32 & 0.78 & {$[0.52,1.17]$} & -1.21 & .227 \\
Amotivation & & $-0.03(0.08)$ & -0.03 & 0.97 & {$[0.83,1.13]$} & -0.39 & .698 \\
Step 2-Amotivation & 0.01 & & & & & & .023 \\
Constant & & $-0.42(0.22)$ & & 0.66 & {$[0.43,1.01]$} & -1.92 & .055 \\
Amotivation & & $-0.04(0.08)$ & -0.05 & 0.96 & {$[0.82,1.12]$} & -0.52 & .602 \\
Default & & $0.40(0.17)$ & 0.20 & 1.49 & {$[1.06,2.10]$} & 2.27 & .023 \\
Step 3-Amotivation & 0.00 & & & & & .435 \\
Constant & & $-0.58(0.30)$ & & 0.56 & {$[0.31,1.01]$} & -1.94 & .053 \\
Amotivation & & $0.03(0.12)$ & -0.04 & 1.03 & {$[0.81,1.30]$} & 0.24 & .812 \\
Default & & $0.69(0.41)$ & 0.20 & 1.99 & {$[0.89,4.49]$} & 1.67 & .096 \\
Amotivation X & & $-0.13(0.16)$ & -0.07 & 0.88 & {$[0.64,1.21]$} & -0.78 & .435 \\
Default & & & & & & & \\
\hline
\end{tabular}

Note. $\beta$ s are $\mathrm{X}$-standardized. $N=544$. 


\section{STEPWISE REGRESSIONS STARTING WITH MOTIVATION STUDY 3 - SUSTAINABILITY}

Table 13. Logistic regression model with the likelihood of participating in the longer version as dependent variable, and goal strivings for making sustainable choices (Step 1), default (Step 2), and interaction effect (Step 3) as independent variables (Study 3).

\begin{tabular}{|c|c|c|c|c|c|c|c|}
\hline & $\Delta R_{N}^{2}$ & $b(S E)$ & $\beta$ & OR & $95 \% \mathrm{Cl} O \mathrm{R}$ & $z$ & $p$ \\
\hline Step 1 - Goal strivings & 0.02 & & & & & & .003 \\
\hline Constant & & $-1.27(0.34)$ & & 0.28 & {$[0.14,0.54]$} & -3.79 & $<.001$ \\
\hline Goal strivings & & $0.20(0.07)$ & 0.27 & 1.23 & {$[1.07,1.40]$} & 2.96 & .003 \\
\hline Step 2 - Goal strivings & 0.01 & & & & & & .025 \\
\hline Constant & & $-1.47(0.35)$ & & 0.23 & {$[0.11,0.45]$} & -4.20 & $<.001$ \\
\hline Goal strivings & & $0.20(0.07)$ & 0.27 & 1.23 & {$[1.07,1.41]$} & 2.96 & .003 \\
\hline Default & & $0.39(0.18)$ & 0.20 & 1.48 & {$[1.05,2.10]$} & 2.23 & .025 \\
\hline Step 3 - Goal Strivings & 0.00 & & & & & & .627 \\
\hline Constant & & $-1.31(0.48)$ & & 0.27 & {$[0.10,0.67]$} & -2.75 & .006 \\
\hline Goal strivings & & $0.17(0.10)$ & 0.27 & 1.19 & {$[0.98,1.44]$} & 1.75 & .081 \\
\hline Default & & $0.08(0.67)$ & 0.19 & 1.08 & {$[0.29,4.07]$} & 0.11 & .909 \\
\hline Goal strivings $X$ & & $0.07(0.14)$ & 0.04 & 1.07 & {$[0.82,1.40]$} & 0.49 & .627 \\
\hline Default & & & & & & & \\
\hline
\end{tabular}

Note. $\beta$ s are X-standardized. $N=544$.

Table 14. Logistic regression model with the likelihood of participating in the longer version as dependent variable, and autonomous motivation for making sustainable choices (Step 1), default (Step 2), and interaction effect (Step 3) as independent variables (Study 3).

\begin{tabular}{lrrrrrrr}
\hline & $\Delta R_{N}^{2}$ & $b(S E)$ & $\beta$ & $O R$ & $95 \%$ Cl OR & $z$ & $p$ \\
\hline Step 1 - Autonomous & 0.01 & & & & & .005 \\
motivation & & & & & & & \\
$\quad$ Constant & & $-1.17(0.37)$ & & 0.31 & {$[0.15,0.64]$} & -3.14 & .002 \\
$\quad$ Autonomous motivation & & $0.16(0.07)$ & 0.21 & 1.17 & {$[1.03,1.34]$} & 2.36 & .018 \\
Step 2-Autonomous & 0.01 & & & & & & .025 \\
motivation & & & & & & & \\
$\quad$ Constant & & $-1.37(0.39)$ & & 0.25 & {$[0.12,0.54]$} & -3.55 & $<.001$
\end{tabular}




\begin{tabular}{|c|c|c|c|c|c|c|c|}
\hline Autonomous motivation & & $0.16(0.07)$ & 0.21 & 1.17 & {$[1.03,1.34]$} & 2.36 & .018 \\
\hline Default & & $0.39(0.18)$ & 0.20 & 1.48 & {$[1.05,2.09]$} & 2.24 & .025 \\
\hline Step 3-Autonomous & 0.00 & & & & & & .956 \\
\hline notivation & & & & & & & \\
\hline Constant & & $-1.35(0.54)$ & & 0.26 & {$[0.09,0.73]$} & -2.50 & .012 \\
\hline Autonomous motivation & & $0.16(0.10)$ & 0.21 & 1.17 & {$[0.97,1.42]$} & 1.60 & .110 \\
\hline Default & & $0.35(0.75)$ & 0.20 & 1.42 & {$[0.33,6.21]$} & 0.47 & .637 \\
\hline Autonomous motivation & & $0.01(0.14)$ & 0.00 & 1.01 & {$[0.77,1.31]$} & 0.06 & .956 \\
\hline
\end{tabular}

Note. $\beta$ s are $\mathrm{X}$-standardized. $N=544$.

Table 15. Logistic regression model with the likelihood of participating in the longer version as dependent variable, and controlled motivation for making sustainable choices (Step 1), default (Step 2), and interaction effect (Step 3) as independent variables (Study 3).

\begin{tabular}{|c|c|c|c|c|c|c|c|}
\hline & $\Delta R_{N}^{2}$ & $b(S E)$ & $\beta$ & OR & $95 \% \mathrm{Cl} O \mathrm{R}$ & $z$ & $p$ \\
\hline $\begin{array}{l}\text { Step } 1 \text { - Controlled } \\
\text { motivation }\end{array}$ & 0.00 & & & & & & .404 \\
\hline Constant & & $-0.54(0.28)$ & $-0 ., 32$ & 0.58 & {$[0.34,1.00]$} & -1.94 & .052 \\
\hline Controlled motivation & & $0.06(0.07)$ & 0.07 & 1.06 & {$[0.92,1.23]$} & 0.83 & .404 \\
\hline $\begin{array}{l}\text { Step } 2 \text { - Controlled } \\
\text { motivation }\end{array}$ & 0.01 & & & & & & .028 \\
\hline Constant & & $-0.69(0.29)$ & & 0.50 & {$[0.28,0.87]$} & -2.42 & .016 \\
\hline Controlled motivation & & $0.05(0.07)$ & 0.06 & 1.05 & {$[0.91,1.21]$} & 0.69 & .491 \\
\hline Default & & $0.38(0.17)$ & 0.19 & 1.47 & {$[1.04,2.07]$} & 2.19 & .029 \\
\hline $\begin{array}{l}\text { Step } 3 \text { - Controlled } \\
\text { motivation }\end{array}$ & 0.00 & & & & & & .185 \\
\hline Constant & & $-0.34(0.39)$ & & 0.71 & {$[0.33,1.54]$} & -0.86 & .392 \\
\hline Controlled motivation & & $-0.05(0.11)$ & 0.05 & 0.95 & {$[0.77,1.17]$} & -0.48 & .628 \\
\hline Default & & $-0.32(0.56)$ & 0.19 & 0.73 & {$[0.24,2.17]$} & -0.57 & .569 \\
\hline Controlled motivation & & $0.19(0.15)$ & 0.12 & 1.21 & {$[0.91,1.62]$} & 1.32 & .186 \\
\hline X Default & & & & & & & \\
\hline
\end{tabular}


Note. $\beta$ s are X-standardized. $N=544$.

Table 16. Logistic regression model with the likelihood of participating in the longer version as dependent variable, and amotivation for making sustainable choices (Step 1), default (Step 2), and interaction effect (Step 3) as independent variables (Study 3).

\begin{tabular}{|c|c|c|c|c|c|c|c|}
\hline & $\Delta R_{N}^{2}$ & $b(S E)$ & $\beta$ & $O R$ & $95 \% \mathrm{Cl} O \mathrm{R}$ & $z$ & $p$ \\
\hline Step 1 - Amotivation & 0.01 & & & & & & .014 \\
\hline Constant & & $-0.02(0.18)$ & & 0.98 & {$[0.69,1.40]$} & -0.10 & .921 \\
\hline Amotivation & & $-0.13(0.07)$ & -0.17 & 0.88 & {$[0.77,1.01]$} & 1.87 & .062 \\
\hline Step 2 - Amotivation & 0.01 & & & & & & .025 \\
\hline Constant & & $-0.22(0.20)$ & & 0.61 & {$[0.54,1.20]$} & -1.06 & .288 \\
\hline Amotivation & & $-0.13(0.07)$ & -0.17 & 0.88 & {$[0.77,1.01]$} & -1.86 & .062 \\
\hline Default & & $0.39(0.18)$ & 0.20 & 1.48 & {$[1.05,2.09]$} & 2.24 & .025 \\
\hline Step 3-Amotivation & 0.00 & & & & & & .362 \\
\hline Constant & & $-0.07(0.26)$ & & 0.94 & {$[0.56,1.57]$} & -0.25 & .802 \\
\hline Amotivation & & $-0.19(0.10)$ & -0.17 & 0.82 & {$[0.67,1.00]$} & 1.93 & .054 \\
\hline Default & & $0.10(0.37)$ & 0.19 & 1.10 & {$[0.54,2.26]$} & 0.27 & .787 \\
\hline Amotivation $\mathrm{X}$ & & $0.13(0.14)$ & 0.08 & 1.14 & {$[0.86,1.49]$} & 0.91 & .363 \\
\hline Default & & & & & & & \\
\hline
\end{tabular}

Note. $\beta$ s are X-standardized. $N=544$. 